\title{
Snap frozen! Capturing two metastable polymorphs in a tetramorphic one- dimensional coordination polymer constructed from cadmium, dithiophosphate, and 4-pyridinealdazine
}

Yee Seng Tan,${ }^{\dagger}$ Alberto Otero-de-la-Roza, ${ }^{\ddagger}$ Mukesh M. Jotani,${ }^{\S}$ and Edward R. T. Tiekink ${ }^{*}, \dagger$

${ }^{\dagger}$ Research Centre for Crystalline Materials, School of Science and Technology, Sunway

University, 47500 Bandar Sunway, Selangor Darul Ehsan, Malaysia

* Departamento de Química Física y Analítica, Facultad de Química and MALTA Consolider Team, Universidad de Oviedo, 33006 Oviedo, Spain

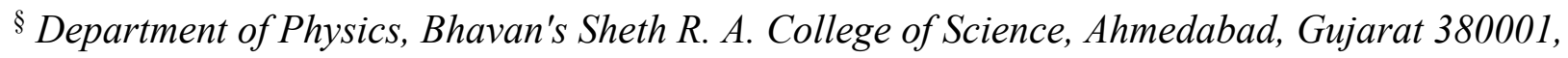
India

Corresponding author's e-mail: edwardt@sunway.edu.my

ABSTRACT: Four polymorphs are described for the one-dimensional coordination polymer $\left\{\mathrm{Cd}\left[\mathrm{S}_{2} \mathrm{P}(\mathrm{OMe})_{2}\right]_{2}(4-\text { pyridine-aldazine })\right\}_{n}$ (1) which features a trans $-\mathrm{N}_{2} \mathrm{~S}_{4}$ distorted octahedral coordination geometry. Lattice energy calculations show the room temperature form, $\mathbf{1} \alpha$, is the thermodynamically stable phase, being $1.52 \mathrm{kcal} / \mathrm{mol}$ more stable than the $\mathbf{1} \boldsymbol{\beta}$ form per unit formula. The latter is formed at $233 \mathrm{~K}$ on cooling $1 \alpha$ based on single crystal data. Single crystals of forms $1 \alpha$ and $1 \beta$ exhibit a reversible single-crystal-single-crystal phase change which also 
occurs in the bulk form as seen in DSC and PXRD experiments. When 1 was "snap frozen" at 100 $\mathrm{K}$ under a cold stream, $\mathbf{1} \boldsymbol{\beta}$ was observed most of the time but sometimes forms $\mathbf{1} \boldsymbol{\gamma}$ and $\mathbf{1} \boldsymbol{\delta}$ were found. When warmed, $\mathbf{1} \beta$ converted to $1 \alpha$ by $293 \mathrm{~K}$, and each of $\mathbf{1} \gamma$ and $\mathbf{1} \delta$ first converted to $\mathbf{1} \beta$ (120-130 and 140-150 K, respectively) and then to $1 \alpha(280 \mathrm{~K})$, correlating with the calculated lattice energies; subsequent cooling only yielded $\mathbf{1} \beta$, indicating $\mathbf{1} \gamma$ and $\mathbf{1} \boldsymbol{\delta}$ are metastable forms. The polymorphs exhibit different molecular packing patterns based on different non-covalent interactions and these have been evaluated by Hirshfeld surface analyses and NCI plots.

\section{INTRODUCTION}

Having influence upon chemical and physical properties of materials related to the agriculture, food, explosives, pharmaceutical, etc. industries, the phenomenon of polymorphism - the ability of a crystalline material to adopt different crystal structures - is of paramount importance. ${ }^{1-3}$ In the context of the drug industry, it is estimated that $30 \%$ of all drugs exhibit polymorphism, ${ }^{4}$ which impacts on pharmaceutically relevant properties and intellectual property issues. ${ }^{1-7}$ This observed propensity toward polymorphism is consistent with computational/crystal structure prediction studies indicating many polymorphs have differences in Gibbs free energies of a few $\mathrm{kcal} / \mathrm{mol}$ only. ${ }^{8-10}$ It is worth mentioning here McCrone's comments concerning polymorphs made some 50 years ago, paraphrasing, that the more effort spent seeking polymorphs, the more polymorphs that will be found. ${ }^{11}$ This axiom is borne out now, especially in the pharmaceutical industry, where polymorph screening often reveals new crystalline forms, including polymorphs. ${ }^{4}$ 
With similarities in lattice energies of polymorphs, ${ }^{8-10,12,13}$ it is not surprising that a polymorph can be converted into another polymorph with the application of an external stimulus, e.g., light, heat, and pressure. Accordingly, single-crystal-single-crystal (SCSC) transformations for polymorphs are very well documented in the crystallographic literature. ${ }^{14}$ Normally, only small changes are noted after a SCSC polymorphic transformation ${ }^{15}$ but sometimes dramatic differences in properties result with retention of crystallinity, ranging from differential proclivities towards $[2+2]$ photodimerization, ${ }^{16}$ distinct color, ${ }^{17}$ and conductivity ${ }^{18}$ profiles and, more recently, mechanical properties. ${ }^{19}$ As indicated above, temperature is a key factor in phase change and in many laboratories, cryo-crystallography is now the norm whereby a crystal is flash-cooled to lowtemperature, typically, $100 \mathrm{~K}$, prior to data collection. While the advantages of low-temperature data collections are wide and varied, ${ }^{20-24}$ there is a potential inherent problem with this approach in that the process of flash-cooling may capture a metastable species, such as a kinetic polymorph rather than the thermodynamic form ${ }^{25}$ or molecules with an unstable conformation. ${ }^{26}$ Herein, the capture of two metastable polymorphs at $100 \mathrm{~K}$ are described.

The one-dimensional coordination polymer $\left\{\mathrm{Cd}\left[\mathrm{S}_{2} \mathrm{P}(\mathrm{OMe})_{2}\right]_{2} \text { (4-pyridine-aldazine) }\right\}_{\mathrm{n}}$ (1) became available during the course of on-going studies into the rationalization of the formation/topology of coordination polymers of the zinc-triad 1,1-dithiolates (e.g., dithiocarbamates, $-\mathrm{S}_{2} \mathrm{CNR}_{2}$, xanthate, ${ }^{-} \mathrm{S}_{2} \mathrm{COR}$, and dithiophosphate, $\left.{ }^{-} \mathrm{S}_{2} \mathrm{P}(\mathrm{OR})_{2}\right)^{27-30}$ and their complexes with potentially bridging bipyridyl-type molecules. ${ }^{31-38}$ In the case of $\mathbf{1}$, temperaturedependent polymorphism was observed (single crystal, PXRD, and DCS): at room temperature, an $\mathbf{1} \boldsymbol{\alpha}$ form was observed which, upon cooling, underwent a SCSC transformation to a $\mathbf{1} \boldsymbol{\beta}$ form which remained until $100 \mathrm{~K}$. When crystals of 1 were placed directly into the cold stream at 100 $\mathrm{K}$, three different forms were found, i.e., $\mathbf{1 \beta}, \mathbf{1} \gamma$, and $\mathbf{1 \delta}$. Heating $\mathbf{1 \beta}$ gave $\mathbf{1} \alpha$, and heating each of 
$1 \gamma$ and $1 \delta$, gave $1 \beta$, and then $1 \alpha$. The structural chemistry of 1 along with computational chemistry and detailed analyses of the calculated Hirshfeld surfaces are described herein. While onedimensional coordination polymers are well documented, ${ }^{39}$ as are SCSC transformations,,${ }^{40,41}$ the present studies describe both SCSC as well as metastable polymorphs of coordination polymer $\mathbf{1}$.

\section{EXPERIMENTAL SECTION}

2.1 Physical characterization. Melting points were measured on a Biobase automatic melting point apparatus MP450. Elemental analyses were performed using a LECO TruSpec $®$ Micro instrument. The IR spectra were obtained on a Bruker Vertex $70 \mathrm{~V}$ spectrophotometer equipped with a platinum ATR. NMR spectra $\left({ }^{1} \mathrm{H},{ }^{13} \mathrm{C}\left\{{ }^{1} \mathrm{H}\right\}\right.$, and $\left.{ }^{31} \mathrm{P}\left\{{ }^{1} \mathrm{H}\right\}\right)$ were recorded in $d_{6}$-DMSO solution on a Bruker Avence III HD $400 \mathrm{MHz}$ FT-NMR spectrometer. The DSC analyses were performed on a Perkin-Elmer DSC-8000 differential scanning calorimeter in the range of -160 to $20{ }^{\circ} \mathrm{C}$ at a rate of $10{ }^{\circ} \mathrm{C} / \mathrm{min}$. Powder X-ray diffraction (PXRD) measurements were performed on a Rigaku SmartLab with CuKa1 radiation $(\lambda=1.54060 \AA)$ in the $2 \theta$ range from 5 to $60^{\circ}$ with a step size of $0.010^{\circ}$. The experimental PXRD patterns were compared to the simulated PXRD patterns calculated from the respective Crystallographic Information File (CIFs) using the Rigaku PDXL structure analysis software package. The powdered samples used in these measurements were prepared by fine grinding the crystalline compound using an agate pestle and mortar.

2.2 Synthesis. The starting materials $\mathrm{Cd}\left(\mathrm{NO}_{3}\right)_{2} \cdot 4 \mathrm{H}_{2} \mathrm{O}, \mathrm{P}_{2} \mathrm{~S}_{5}$ (Aldrich), $\mathrm{MeOH}$ (Merck), $\mathrm{CS}_{2}$ (Pancrea), and $\mathrm{NaOH}(50 \% w / w)$ solution (Merck) were used without further purification. The $\mathrm{Cd}\left[\mathrm{S}_{2} \mathrm{P}(\mathrm{OMe})_{2}\right]_{2}$ compound was prepared in a high yield from the in situ reaction of 
$\mathrm{Cd}\left(\mathrm{NO}_{3}\right)_{2} .4 \mathrm{H}_{2} \mathrm{O}, \mathrm{P}_{4} \mathrm{~S}_{10}, \mathrm{MeOH}, \mathrm{CS}_{2}$, and $\mathrm{NaOH}\left(50 \%\right.$ w/w) following standard procedures. ${ }^{34} 4-$ Pyridinealdazine $(0.25 \mathrm{~g}, 1.19 \mathrm{mmol})$ was taken into a mixture of chloroform-acetonitrile solution $(3: 1 ; 20 \mathrm{ml})$ and added slowly to a $\mathrm{Cd}\left[\mathrm{S}_{2} \mathrm{P}(\mathrm{OMe})_{2}\right]_{2}(0.50 \mathrm{~g}, 1.17 \mathrm{mmol})$ chloroform-acetonitrile solution $(3: 1 ; 30 \mathrm{ml})$. The solution was stirred at room temperature for $1 \mathrm{~h}$, filtered, and the filtrate was left for slow evaporation at room condition. Yellow blocks of $\mathbf{1}$ were formed after one week. M. pt: 422.0-422.8 K (dec.). Yield: 0.47 g (63 \%). Anal. Calcd for $\mathrm{C}_{16} \mathrm{H}_{22} \mathrm{CdN}_{4} \mathrm{O}_{4} \mathrm{P}_{2} \mathrm{~S}_{4}$ : C 30.17; H 3.48; N 8.80 \%. Found: C30.14; H 3.47; N $8.72 \%$. IR $\left(\mathrm{cm}^{-1}\right): 1606(\mathrm{~m}) \mathrm{v}(\mathrm{C}=\mathrm{N}) ; 1060(\mathrm{~m})$ $v(\mathrm{C}-\mathrm{O}) ; 1002(\mathrm{~s}) v(\mathrm{P}-\mathrm{O}) ; 647(\mathrm{~s}) v_{\text {asym }}(\mathrm{P}-\mathrm{S}) ; 514(\mathrm{~m}) v_{\text {sym }}(\mathrm{P}-\mathrm{S}) .{ }^{1} \mathrm{H}$ NMR: $\delta 8.75(d, 4 \mathrm{H}, o$-aryl$\left.\mathrm{H}, \mathrm{J}_{\mathrm{HH}}=5.84 \mathrm{~Hz}\right), 8.69(s, 2 \mathrm{H}, \mathrm{N}=\mathrm{CH}), 7.82\left(d, 4 \mathrm{H}, m\right.$-aryl- $\left.\mathrm{H}, \mathrm{J}_{\mathrm{HH}}=5.84 \mathrm{~Hz}\right), 3.59\left(d, 12 \mathrm{H}, \mathrm{CH}_{3}\right.$, $\left.\mathrm{J}_{\mathrm{PH}}=14.80 \mathrm{~Hz}\right) \mathrm{ppm} .{ }^{13} \mathrm{C}\left\{{ }^{1} \mathrm{H}\right\}: \delta 159.6(\mathrm{C}=\mathrm{N}), 150.5\left(o-\mathrm{C}_{5} \mathrm{H}_{4} \mathrm{~N}\right), 140.5\left(i-\mathrm{C}_{5} \mathrm{H}_{4} \mathrm{~N}\right), 122.1(m-$ $\left.\mathrm{C}_{5} \mathrm{H}_{4} \mathrm{~N}\right), 52.8\left(d, \mathrm{OCH}_{3} \mathrm{JPC}_{\mathrm{PC}}=6.46 \mathrm{~Hz}\right) \mathrm{ppm} .{ }^{31} \mathrm{P}\left\{{ }^{1} \mathrm{H}\right\}: \delta 115.5 \mathrm{ppm}$.

2.3 Single crystal X-ray crystallography. Crystal and refinement details for $\mathbf{1} \alpha-\mathbf{1} \delta$ are given in Table 1. Intensity data were measured at on a Rigaku/Oxford Diffraction XtaLAB Synergy diffractometer (Dualflex, AtlasS2) fitted with $\mathrm{CuK} \alpha$ radiation $\left(\lambda=1.54178 \AA\right.$ ) so that $\theta_{\max }=67.1^{\circ}$. Data processing and Gaussian absorption corrections were accomplished with CrysAlis PRO. ${ }^{42}$ The structures were solved by direct methods. ${ }^{43}$ Full-matrix least squares refinement on $F^{2}$ with anisotropic displacement parameters for all non-hydrogen atoms was performed. ${ }^{44}$ The C-bound $\mathrm{H}$ atoms were placed on stereochemical grounds and refined with fixed geometries. A weighting scheme of the form $w=1 /\left[\sigma^{2}\left(F_{0}^{2}\right)+(a P)^{2}+b P\right]$ where $P=\left(F_{0}^{2}+2 F_{\mathrm{c}}^{2}\right) / 3$ was introduced in each case. In the refinement of $\mathbf{1} \gamma$, three reflections, i.e., (1 1113 ), (2 1113 ), and (1 122 2), were omitted from the final cycles of refinement owing to poor agreement. The programs WinGX, ${ }^{45}$ ORTEP-3 for Windows ${ }^{45}$ PLATON,${ }^{46}$ and DIAMOND ${ }^{47}$ were also used in the study. 
2.4 Computational chemistry. Density-functional theory (DFT) calculations were carried out using the Quantum ESPRESSO software package. ${ }^{48}$ The projector augmented wave (PAW) method $^{49}$ was used with the B86bPBE functional ${ }^{50,51}$ augmented with the exchange-hole dispersion moment (XDM) model. ${ }^{52,53}$ The calculation parameters were chosen to ensure a satisfactory convergence of the total energy: plane-wave cut-off (80 Ry), density cut-off (800 Ry), and k-point sampling $(2 \times 2 \times 2)$. The all-electron and valence densities were obtained using the Quantum ESPRESSO post-processing program using a 200 Ry plane-wave cut-off and subsequently analyzed with CRITIC2. ${ }^{54}$ Non-covalent interaction (NCI) plots ${ }^{55,56}$ and calculated atomic (Bader) charges with the Yu-Trinkle (YT) $\operatorname{method}^{57}$ were also employed in the study. 
Table 1. Crystallographic data and refinement details for polymorphs $\mathbf{1} \boldsymbol{\alpha}-\mathbf{1 \delta}^{\mathrm{a}}$

\begin{tabular}{|c|c|c|c|c|}
\hline Compound & $1 \alpha$ & $1 \beta$ & $1 \gamma$ & $1 \delta$ \\
\hline Temperature/K & 293 & 100 & 100 & 100 \\
\hline Crystal size $/ \mathrm{mm}^{3}$ & $0.08 \times 0.08 \times 0.17$ & $0.07 \times 0.15 \times 0.18$ & $0.05 \times 0.06 \times 0.12$ & $0.04 \times 0.08 \times 0.13$ \\
\hline Crystal system & triclinic & monoclinic & triclinic & triclinic \\
\hline Space group & $P \overline{1}$ & $C 2 / c$ & $P \overline{1}$ & $P \overline{1}$ \\
\hline$a / \AA$ & $6.6965(2)$ & $20.7967(2)$ & $6.7627(1)$ & $6.4931(4)$ \\
\hline$b / \AA$ & $9.8315(2)$ & $13.9117(2)$ & $13.4029(1)$ & $9.4186(7)$ \\
\hline$c / \AA$ & $9.9324(2)$ & $16.9722(1)$ & $13.8685(1)$ & $10.6041(4)$ \\
\hline$\alpha /^{\circ}$ & $92.039(2)$ & 90 & $87.825(1)$ & $98.184(4)$ \\
\hline$\beta /^{\circ}$ & $102.068(2)$ & $90.989(1)$ & $81.011(1)$ & $97.197(4)$ \\
\hline$\gamma, /{ }^{\circ}$ & $91.465(2)$ & 90 & $79.848(1)$ & $106.252(6)$ \\
\hline$V / \AA^{3}$ & $638.69(3)$ & 4909.62(9) & $1222.09(2)$ & $606.87(7)$ \\
\hline$Z$ & 1 & 8 & 2 & 1 \\
\hline$D_{\mathrm{c}} / \mathrm{g} \mathrm{cm}^{-3}$ & 1.656 & 1.723 & 1.731 & 1.743 \\
\hline$\lambda(\mathrm{Mo} K \alpha) / \mathrm{mm}^{-1}$ & 11.351 & 11.814 & 11.865 & 11.947 \\
\hline
\end{tabular}




\begin{tabular}{|c|c|c|c|c|}
\hline Measured data & 14906 & 31963 & 62940 & 12979 \\
\hline$\theta$ range $/^{\circ}$ & $4.5-67.1$ & $3.8-67.1$ & $3.2-67.1$ & $4.3-67.1$ \\
\hline Unique data & 2261 & 4375 & 4352 & 2171 \\
\hline Observed data $(I \geq 2.0 \sigma(I))$ & 2237 & 4321 & 4214 & 2127 \\
\hline No. parameters & 144 & 284 & 284 & 144 \\
\hline$R$, obs. data; all data & $0.029 ; 0.029$ & $0.019 ; 0.019$ & $0.022 ; 0.023$ & $0.026 ; 0.026$ \\
\hline$a ; b$ in weighting scheme & $0.044 ; 0.298$ & $0.029 ; 5.745$ & $0.036 ; 0.936$ & $0.042 ; 0.360$ \\
\hline$R_{\mathrm{w}}$, obs. data; all data & $0.074 ; 0.074$ & $0.050 ; 0.050$ & $0.061 ; 0.062$ & $0.067 ; 0.068$ \\
\hline \multicolumn{5}{|l|}{ Range of residual electron } \\
\hline density peaks/e $\AA^{-3}$ & $-0.75-0.57$ & $-0.51-0.90$ & $-0.69-0.74$ & $-0.80-0.98$ \\
\hline
\end{tabular}

${ }^{a}$ Data common to all four structures: formula: $\mathrm{C}_{16} \mathrm{H}_{22} \mathrm{CdN}_{4} \mathrm{O}_{4} \mathrm{P}_{2} \mathrm{~S}_{4}$; formula weight: 636.95 ; crystal color: yellow. 


\section{RESULTS AND DISCUSSION}

3.1 Molecular structures. The $\left\{\mathrm{Cd}\left[\mathrm{S}_{2} \mathrm{P}(\mathrm{OMe})_{2}\right]_{2} \text { (4-pyridine-aldazine) }\right\}_{\mathrm{n}}(\mathbf{1})$ compound has been crystallized in four polymorphs, Figure 1 . Form $\mathbf{1} \alpha$ crystallizes in the triclinic space group $P \overline{1}$ with the cadmium atom located on a center of inversion and the 4-pyridine-aldazine (4-PyAld) molecule located about a center of inversion so the asymmetric unit comprises half the repeat unit of the one-dimensional coordination polymer. In form $\mathbf{1 \beta}$, which crystallizes in the monoclinic space group $C 2 / c$, the cadmium atom lies in a general position but the N2- and N4- 4-PyAld molecules are situated about a center of inversion and a 2-fold axis of symmetry, respectively. Both the $\mathbf{1} \gamma$ and $\mathbf{1} \boldsymbol{\delta}$ forms crystallize in triclinic space group $P \overline{1}$. For $\mathbf{1} \gamma$, the cadmium lies in a general position and each 4-PyAld molecule is situated about a center of inversion. For $\mathbf{1 \delta}$, the asymmetric unit is as for $\mathbf{1 \alpha}$, i.e., with the cadmium atom and 4-PyAld molecule located on and about a center of inversion, respectively.

Consistent with the designation of $\mathbf{1} \boldsymbol{\alpha}-\mathbf{1 \delta}$ as polymorphs, the molecular structures are the same, at least to a first approximation; selected geometric parameters are collected in Table S1. The cadmium atom is chelated by two dithiophosphate ligands and two nitrogen atoms derived from bidentate, bridging 4-PyAld ligands. The resulting trans $-\mathrm{N}_{2} \mathrm{~S}_{4}$ donor set defines a distorted octahedron; the acute $\mathrm{S}-\mathrm{Cd}-\mathrm{S}$ chelate angle subtended by the dithiophosphate ligands play a major role in distorting the octahedral geometry. There are systematic differences in the $\mathrm{Cd}-\mathrm{S}$ bond lengths with the difference between the longest and shortest bonds being $0.03,0.04,0.08$, and 0.10 $\AA$ for $\mathbf{1} \boldsymbol{\alpha}-\mathbf{1 \delta}$, respectively. Similarly, the $\mathrm{Cd}-\mathrm{N}$ bond lengths are experimentally distinct, ranging from a short 2.3925(15) in $\mathbf{1 \beta}$ to a long 2.435(2) in $\mathbf{1 \delta}$. Further discussion on the variations in bond lengths about the cadmium atoms is presented below. 

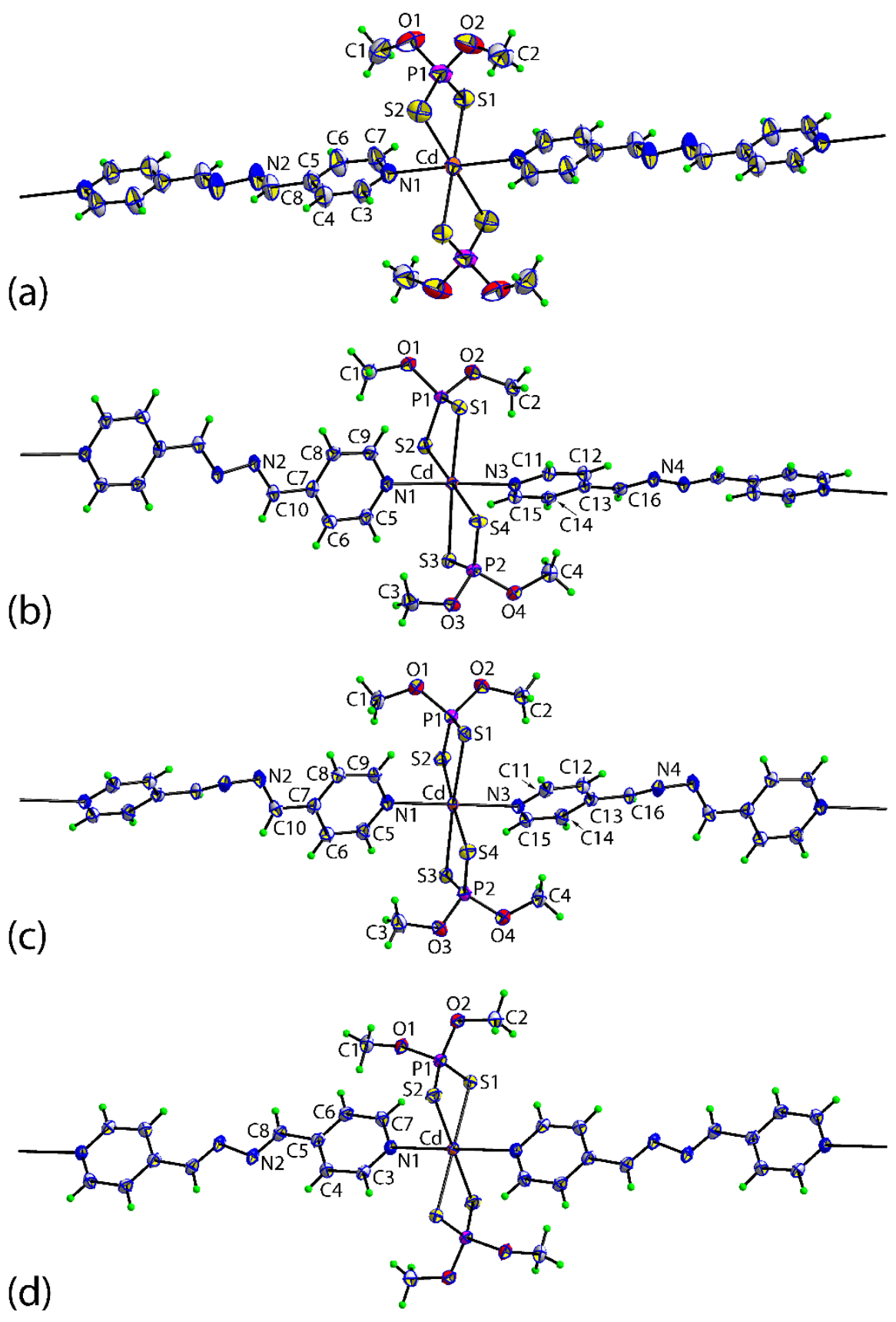

Figure 1. Extended coordination geometries in the one-dimensional coordination polymers in tetramorphic $\left\{\mathrm{Cd}\left[\mathrm{S}_{2} \mathrm{P}(\mathrm{OMe})_{2}\right]_{2} \text { (4-pyridine-aldazine) }\right\}_{n}$ (1): (a) $\mathbf{1} \boldsymbol{\alpha}$ form, (b) $\mathbf{1} \boldsymbol{\beta}$, (c) $\mathbf{1} \boldsymbol{\gamma}$, and (d) $\mathbf{1} \boldsymbol{\delta}$ form, showing atom labeling schemes and displacement parameters at the $70 \%$ probability level. 
There are also experimentally significant variations in bond and torsion angles, for a listing see Table S1 and an overlay diagram shown in Figure S1(a). For example, while for $\mathbf{1} \boldsymbol{\alpha}$ and $\mathbf{1 \delta}$, the trans angles are constrained by symmetry to be $180^{\circ}$, deviations by over $6^{\circ}(\mathbf{1 \beta})$ are evident. Additional differences are noted in conformations of various residues as evidenced in the $\mathrm{C}_{\text {pyridyl- }}$ $\mathrm{C}_{\mathrm{pyridy}}-\mathrm{C}_{\mathrm{imin}}-\mathrm{N}$ torsion angles, which vary up to nearly $21^{\circ}(\mathbf{1} \boldsymbol{\beta}$ and $\mathbf{1} \gamma)$, and in the relative dispositions of the methoxy groups with the $\mathrm{S}-\mathrm{P}-\mathrm{O}-\mathrm{C}$ torsion angles varying up to $50^{\circ}$ ( $1 \boldsymbol{\delta}$ and 1a). However, the most dramatic differences between the molecular geometries are seen in the dihedral angles between the pyridyl residues of the 4-pyridine-aldazine ligands, which vary by over $50^{\circ}$. A plot of the dihedral angles found in the over 300 literature precedents of 4-pyridinealdazine molecules extracted from the Cambridge Structural Database is shown in Figure S1(b), ${ }^{58}$ shows well over $80 \%$ of examples have dihedral angles less than $20^{\circ}$, as in centrosymmetric $\mathbf{1 \alpha}$ and $\mathbf{1} \boldsymbol{\delta}$ but in contrast to the wide angles in $\mathbf{1 \beta}\left(53.78(6)^{\circ}\right)$ and $\mathbf{1} \gamma\left(32.11(9)^{\circ}\right)$.

Side-on and end-on views of the resultant coordination polymers for $\mathbf{1} \boldsymbol{\alpha}-\mathbf{1} \boldsymbol{\delta}$ are shown in Figure 2. The similarity is obvious. The pitch of the coordination polymers varies from $\mathrm{Cd}{ }^{\cdots} \mathrm{Cd}=16.04$ $\AA$ in $\mathbf{1} \gamma$ to $16.32 \AA$ in $\mathbf{1 \delta}$, and the $\mathrm{Cd} \cdots \mathrm{Cd} \cdots \mathrm{Cd}$ angle deviates from $180^{\circ}$ only in $\mathbf{1 \beta}\left(177.733(4)^{\circ}\right)$. 
(a)

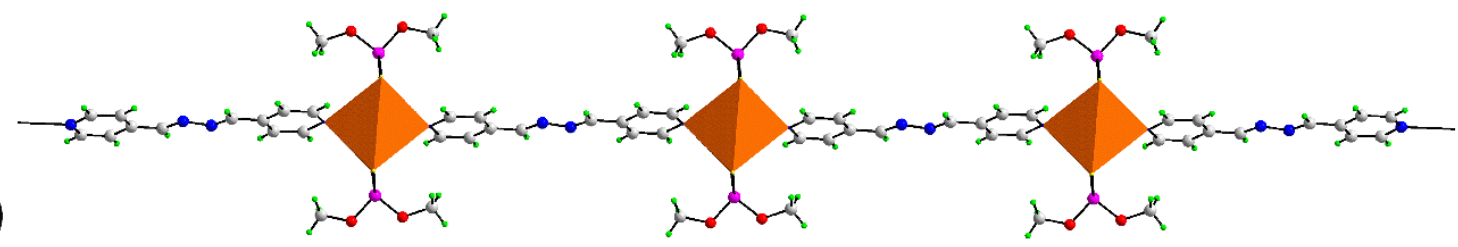

(b)

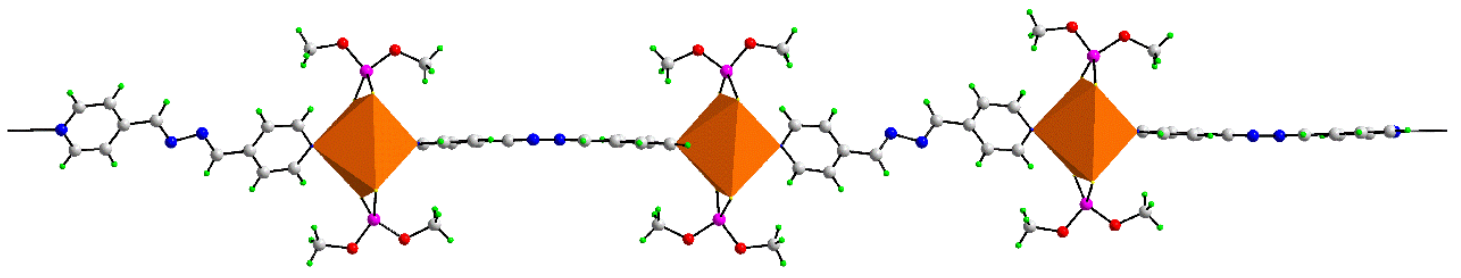

(c)

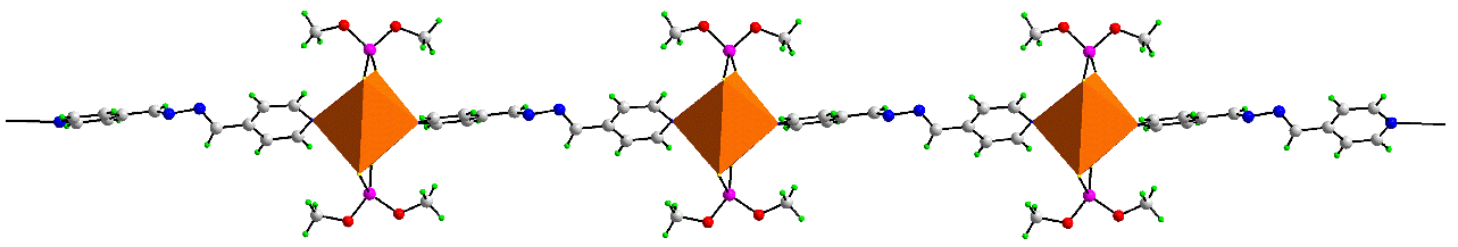

(d)

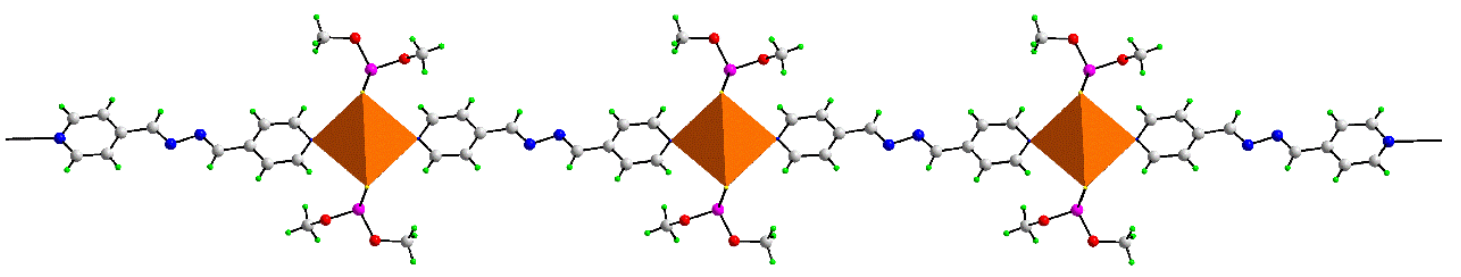

(e)
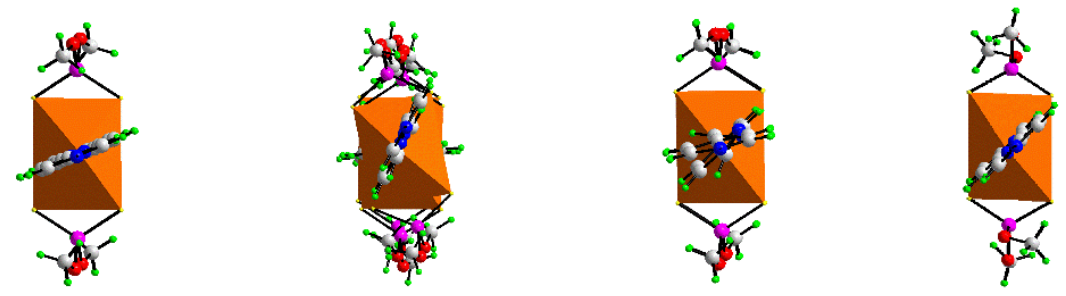

Figure 2. Side-on views of the one-dimensional coordination polymers in tetramorphic $\left\{\mathrm{Cd}\left[\mathrm{S}_{2} \mathrm{P}(\mathrm{OMe})_{2}\right]_{2}(4-\text { pyridine-aldazine })\right\}_{n}$ (1): (a) $\mathbf{1} \boldsymbol{\alpha}$ form, (b) $\mathbf{1} \boldsymbol{\beta}$, (c) $\mathbf{1} \gamma$ and (d) $\mathbf{1} \boldsymbol{\delta}$, and (e) endon views of, left to right, forms $\mathbf{1} \boldsymbol{\alpha}-\mathbf{1} \boldsymbol{\delta}$.

3.2 Molecular packing. The molecular packing of polymorphs $1 \alpha-1 \beta$ feature weak, non-covalent interactions and the geometric parameters characterizing these are given in Table 2. The only 
directional interactions identified in the crystal of form $\mathbf{1} \alpha$, are pyridyl-C- $\mathrm{H} \cdots \mathrm{O}$ (methoxy) contacts which extend laterally between off-set coordination polymers to form a supramolecular layer parallel to (1 0 1), as shown in Figure 3(a). As illustrated in Figure 3(b), the layers stack without directional interactions between them.

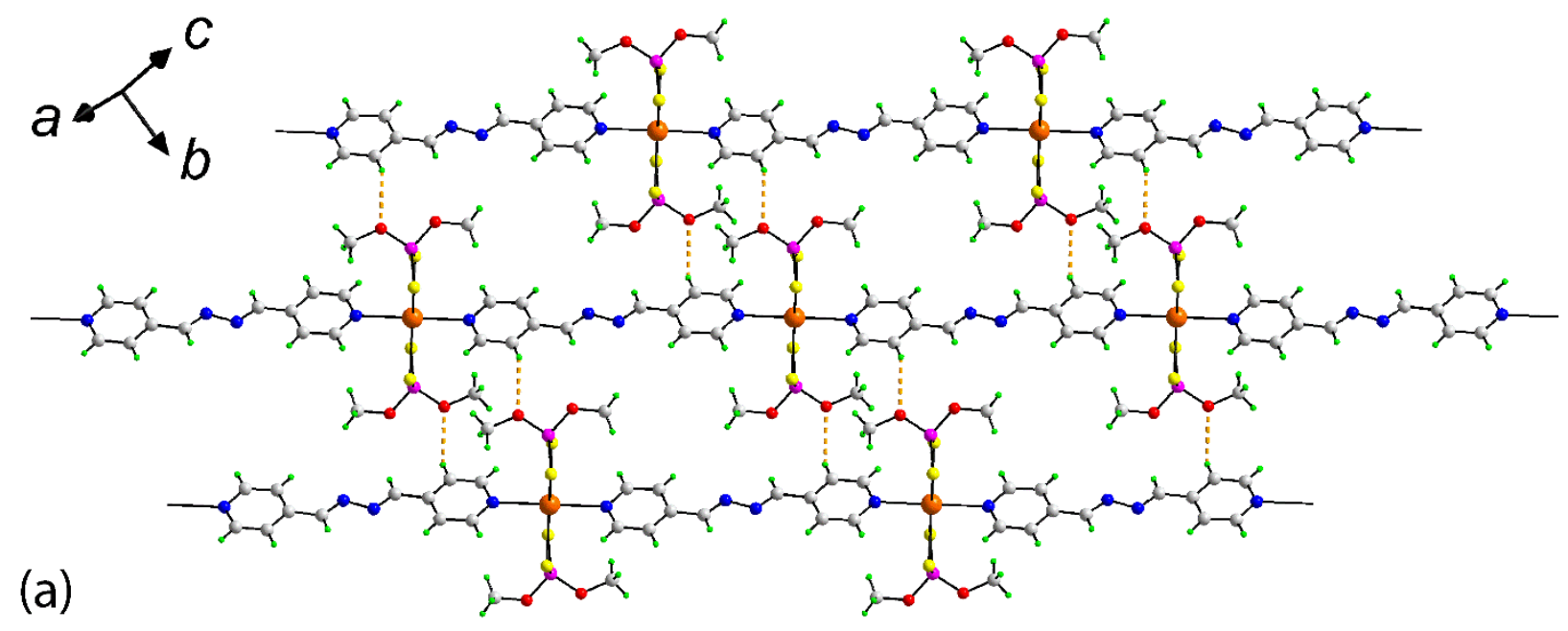

(b)

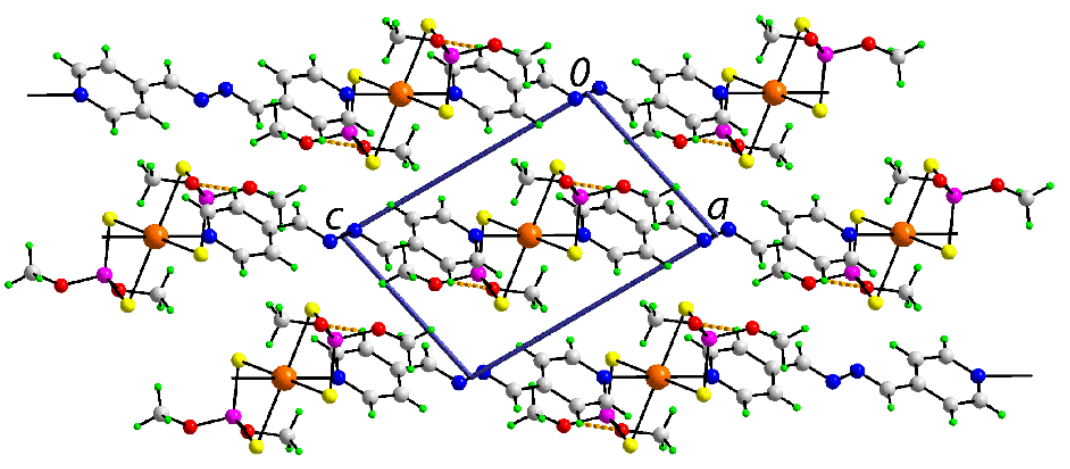

Figure 3. Molecular packing in the $1 \alpha$ form: (a) supramolecular layer sustained by pyridyl-C$\mathrm{H} \cdots \mathrm{O}$ (methoxy) interactions (shown as orange dashed lines) and (b) view in projection down the $b$-axis highlighting the stacking of layers. 
Supramolecular layers are also noted in the crystal of form $1 \boldsymbol{\beta}$ but in this case these are mediated by pyridyl-C-H $-\mathrm{N}$ S interactions, Figure 4(a). The layers lie parallel to $\left(\begin{array}{lll}0 & 1 & 0\end{array}\right)$ and are connected into a three-dimensional architecture by weak methoxy-C- $\mathrm{H}^{\cdots} \pi$ (pyridyl) interactions, Figure 4(b).<smiles>[CH2][CH][CH][CH2]</smiles>

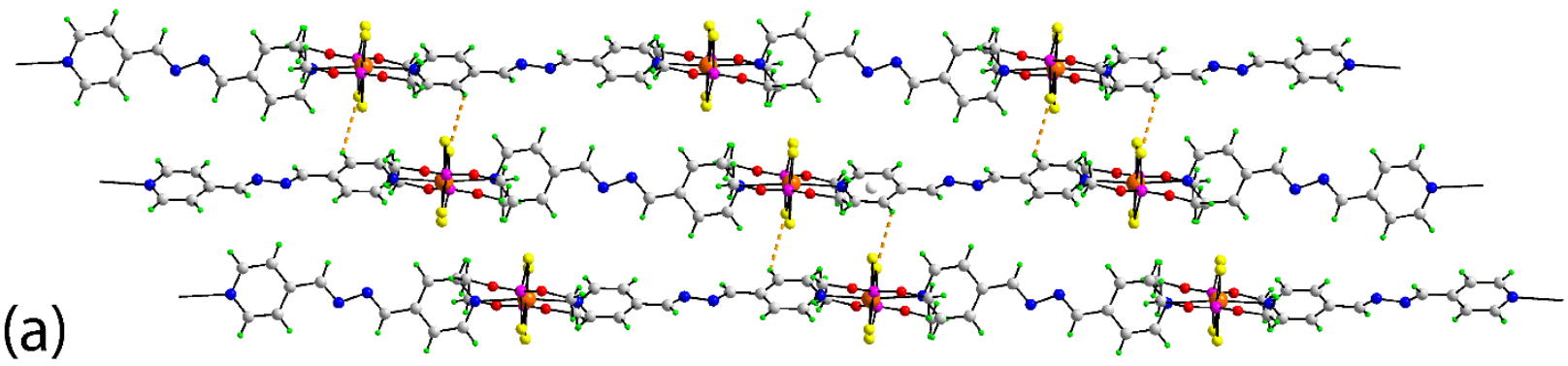

(b)

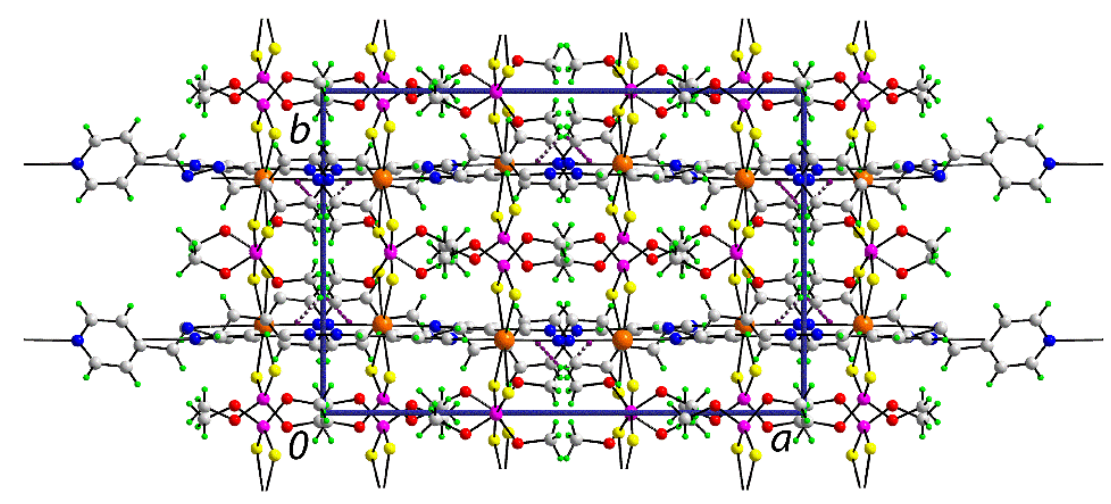

Figure 4. Molecular packing in the $\mathbf{1} \boldsymbol{\beta}$ form: (a) supramolecular layer sustained by pyridyl-C$\mathrm{H}^{\cdots} \mathrm{S}$ interactions (shown as orange dashed lines) and (b) view in projection down the $c$-axis with methoxy-C-H $\mathrm{H}^{\cdots} \pi$ (pyridyl) interactions shown as purple dashed lines (the $\mathrm{C}-\mathrm{H}^{\cdots} \mathrm{S}$ contacts are obscured).

Very similar supramolecular layers to those just described are found in the crystal of form $\mathbf{1} \boldsymbol{\gamma}$, Figure 5(a). Whereas in the former, only one dithiophosphate ligand was involved in forming pyridyl-C- $\mathrm{H} \cdots \mathrm{S}$ interactions but, from symmetry, in the $\mathbf{1} \gamma$ form, both dithiophosphate ligands 
participate in their formation. Successive layers, which lie parallel to $\left(\begin{array}{lll}0 & 0 & 1\end{array}\right)$, are off-set giving rise to an $\cdots \mathrm{ABAB} \cdots$ pattern and allowing inter-digitation of the methoxy groups, Figure 5(b). Despite this, no directional interactions between the layers are apparent. 
Table 2 A summary of intermolecular interactions $\left(\mathrm{A}-\mathrm{H} \cdots \mathrm{B} ; \AA,{ }^{\circ}\right)$ operating in the crystal structures of polymorphs $\mathbf{1} \boldsymbol{\alpha}-\mathbf{1 \delta}$

\begin{tabular}{|c|c|c|c|c|c|c|c|}
\hline A & $\mathrm{H}$ & $\mathrm{B}$ & $\mathrm{A}-\mathrm{H}$ & $\mathrm{H}^{\cdots} \mathrm{B}$ & $A \cdots B$ & $\mathrm{~A}-\mathrm{H}^{\cdots} \mathrm{B}$ & $\begin{array}{l}\text { Symmetry } \\
\text { operation }\end{array}$ \\
\hline
\end{tabular}

\section{$1 \delta$}

C4

$\mathrm{H} 4 \mathrm{O} 2$

0.93

2.48

$3.216(5)$

136

$x,-1+y, z$

$1 \beta$

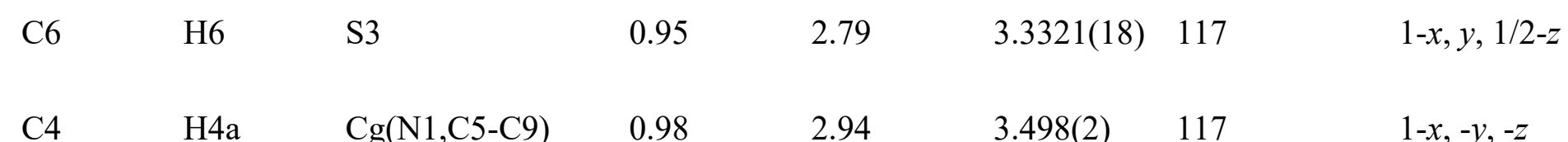

C4

H4a

$\mathrm{Cg}(\mathrm{N} 1, \mathrm{C} 5-\mathrm{C} 9)$

0.98

2.94

$3.498(2)$

$1-x,-y,-z$

$1 \gamma$

$\begin{array}{lll}\mathrm{C} 12 & \mathrm{H} 12 & \mathrm{~S} 2\end{array}$

0.95

2.84

$3.499(2)$

127

$1+x, y, z$

$1 \delta$

C8

H8

O2

0.95

2.52

$3.427(3)$

159

$1-x, 1-y,-z$ 


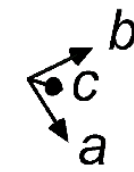

(a)
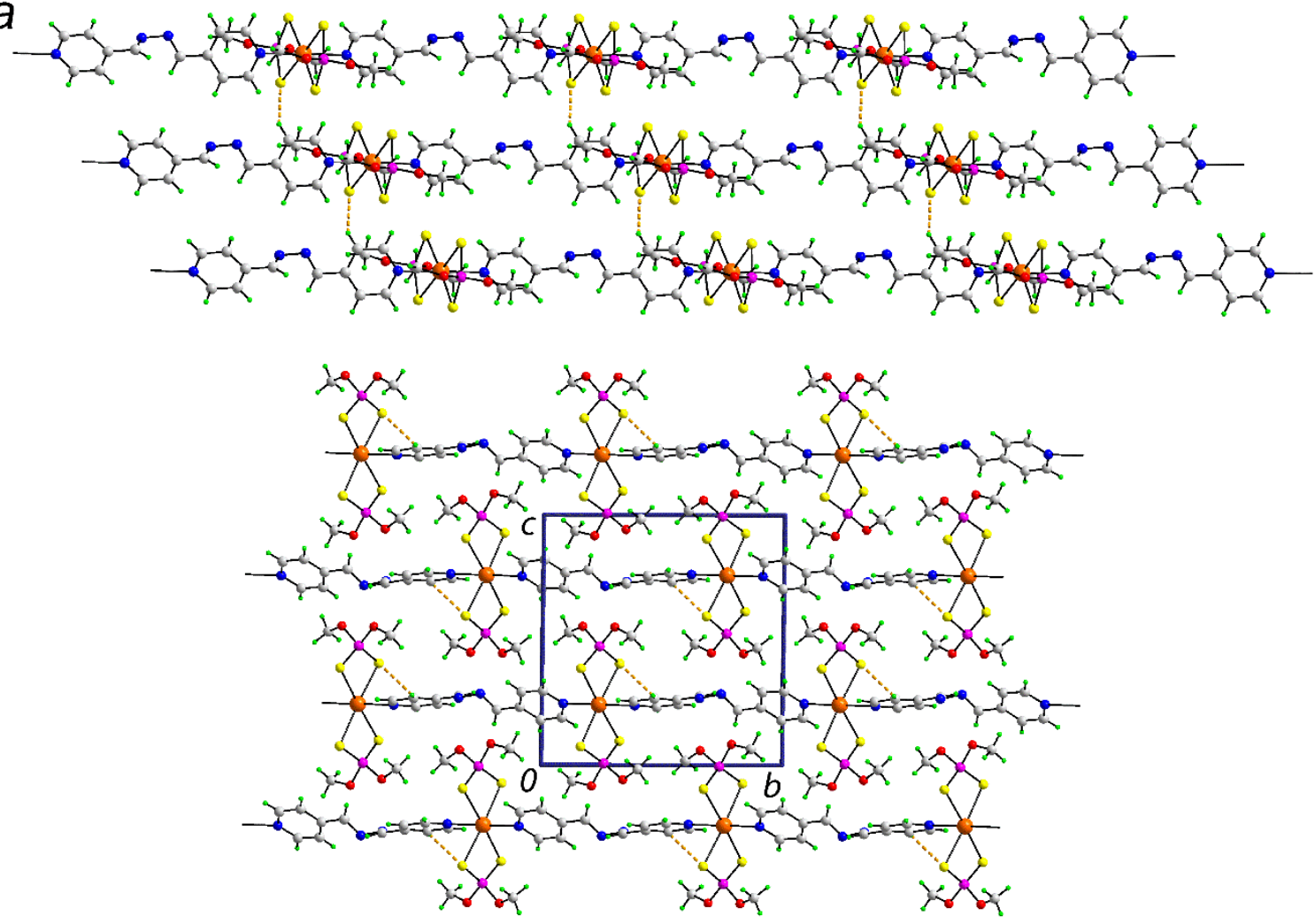

(b)

Figure 5. Molecular packing in the $\mathbf{1} \gamma$ form: (a) supramolecular layer sustained by pyridyl-C$\mathrm{H}^{\cdots} \mathrm{S}$ interactions (shown as orange dashed lines) and (b) view in projection down the $a$-axis highlighting the inter-digitation of layers along the $b$-axis.

The molecular packing of form $\mathbf{1} \boldsymbol{\delta}$ resembles closely that described above for $\mathbf{1} \boldsymbol{\alpha}$. Indeed, a comparison of the supramolecular layers for the two forms shown in Figures 3(a) and 6(a), respectively, highlights this. The key difference between forms $\mathbf{1} \boldsymbol{\alpha}$ and $\mathbf{1} \boldsymbol{\delta}$ relates to the donor

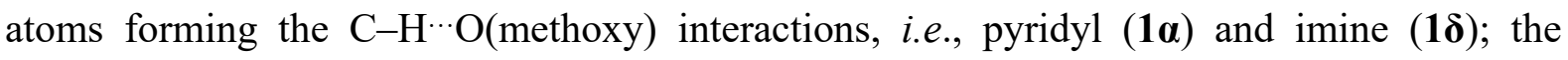
acceptor atom is a methoxy-O atom in each case. The supramolecular layer in form $\mathbf{1 \delta}$ lies parallel to $\left(\begin{array}{lll}1 & 1 & 0\end{array}\right)$ and successive layers inter-digitate. Again, as form $\mathbf{1} \boldsymbol{\alpha}$, no directional interactions connecting layers are apparent in form 18, Figure 6(b). 


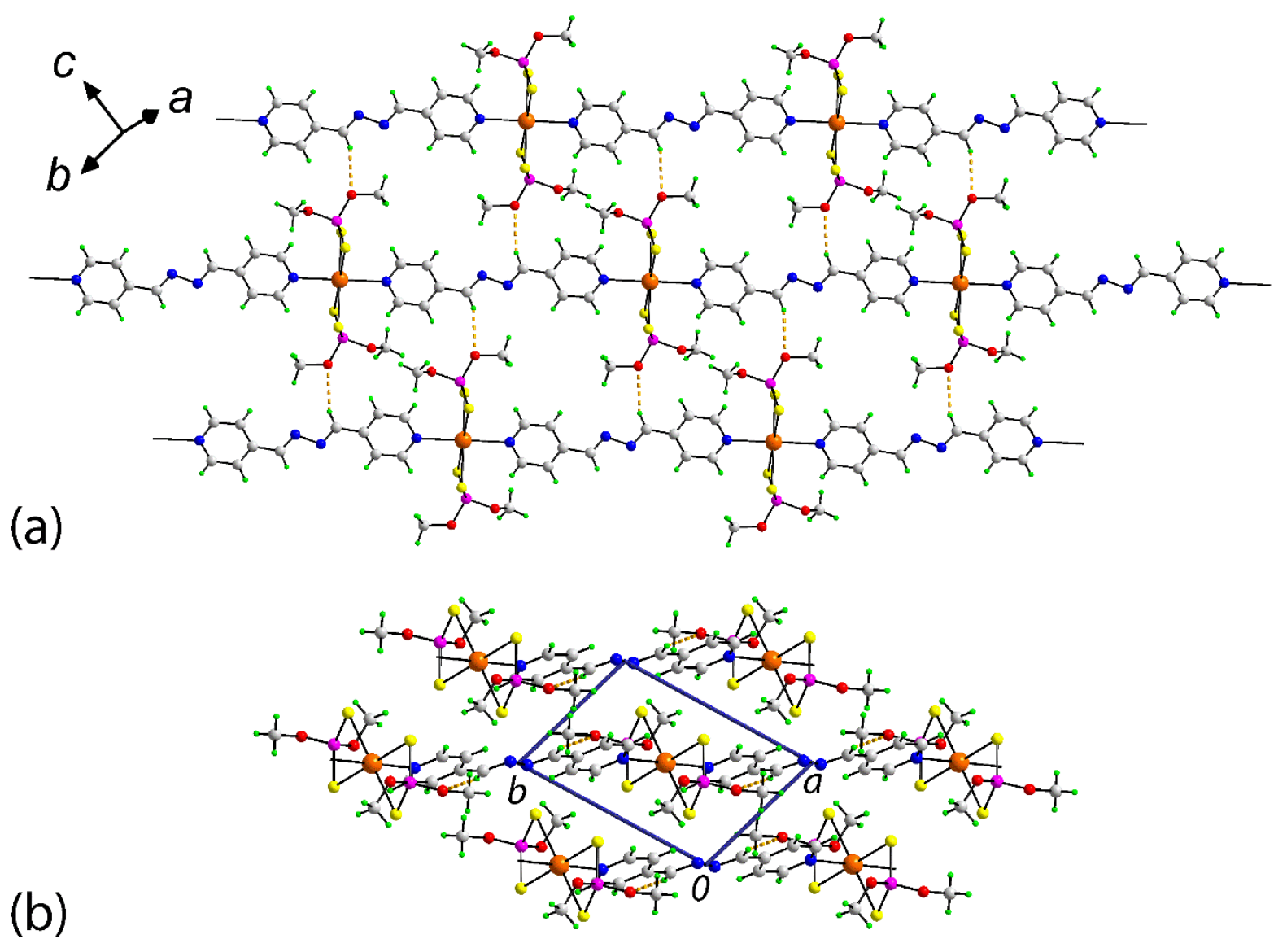

Figure 6. Molecular packing in the $\mathbf{1} \boldsymbol{\delta}$ form: (a) supramolecular layer sustained by imine-C$\mathrm{H}^{\cdots} \mathrm{O}$ (methoxy) interactions (shown as orange dashed lines) and (b) view in projection down the $c$-axis highlighting the stacking of layers.

\subsection{Non-covalent interaction (NCI) plots}

NCI plots are a convenient tool with which one can identify supramolecular contacts in the molecular packing contributing to the overall binding of a molecular crystal. ${ }^{55,56}$ Although qualitative in nature, the color scheme in NCI plots informs whether a given molecular contact contributes more or less to binding, which is achieved by mapping a color scale on the electron density values in the intermolecular space. NCI plots highlighting inter-chain interactions for $\mathbf{1 \alpha}-\mathbf{1 \delta}$ are illustrated in Figure 7, where all unique intermolecular contacts in each of the crystal 
forms are considered. In an NCI plot, the green regions indicate weak and non-directional interactions between the different moieties in all four polymorphs.

The common feature of all four polymorphs is the presence of weak $\mathrm{C}-\mathrm{H} \cdots \mathrm{O}, \mathrm{C}-\mathrm{H} \cdots \pi$, and $\mathrm{H} \cdots \mathrm{H}$ interactions in the inter-chain region and all of them except for $\mathbf{1} \boldsymbol{\delta}$, present evidence of a small $\mathrm{S} \cdots \pi$ interaction. It is also evident $\pi \cdots \pi$ interactions are present in perpendicular conformations between pyridine rings in $1 \alpha, \mathbf{1 \beta}$, and $\mathbf{1} \gamma$, as highlighted by the prominent green regions of Figure 7(b), 7(d), and 7(g). In addition, $1 \alpha$ presents weak $\mathrm{O}($ lone-pair) $\cdots \pi$ and $\mathrm{C}-$ $\mathrm{H} \cdots \mathrm{S}$ interactions. All interactions are relatively weak and it is likely that long-range dispersion effects are a major contributing factor determining the structure of these crystals, as evidenced by the tight packing of the different residues.

(a)
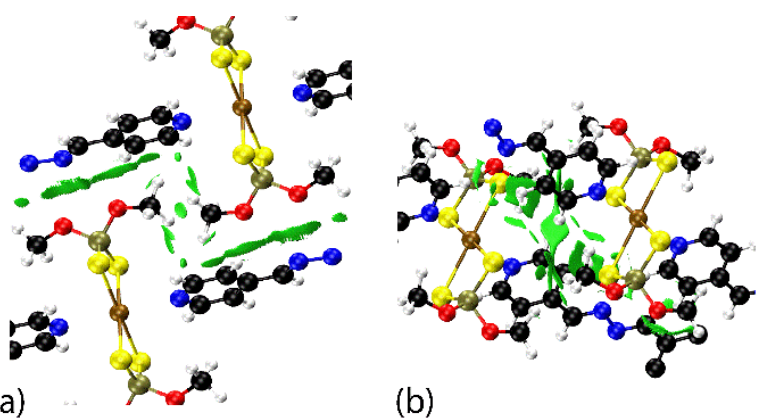

(b)
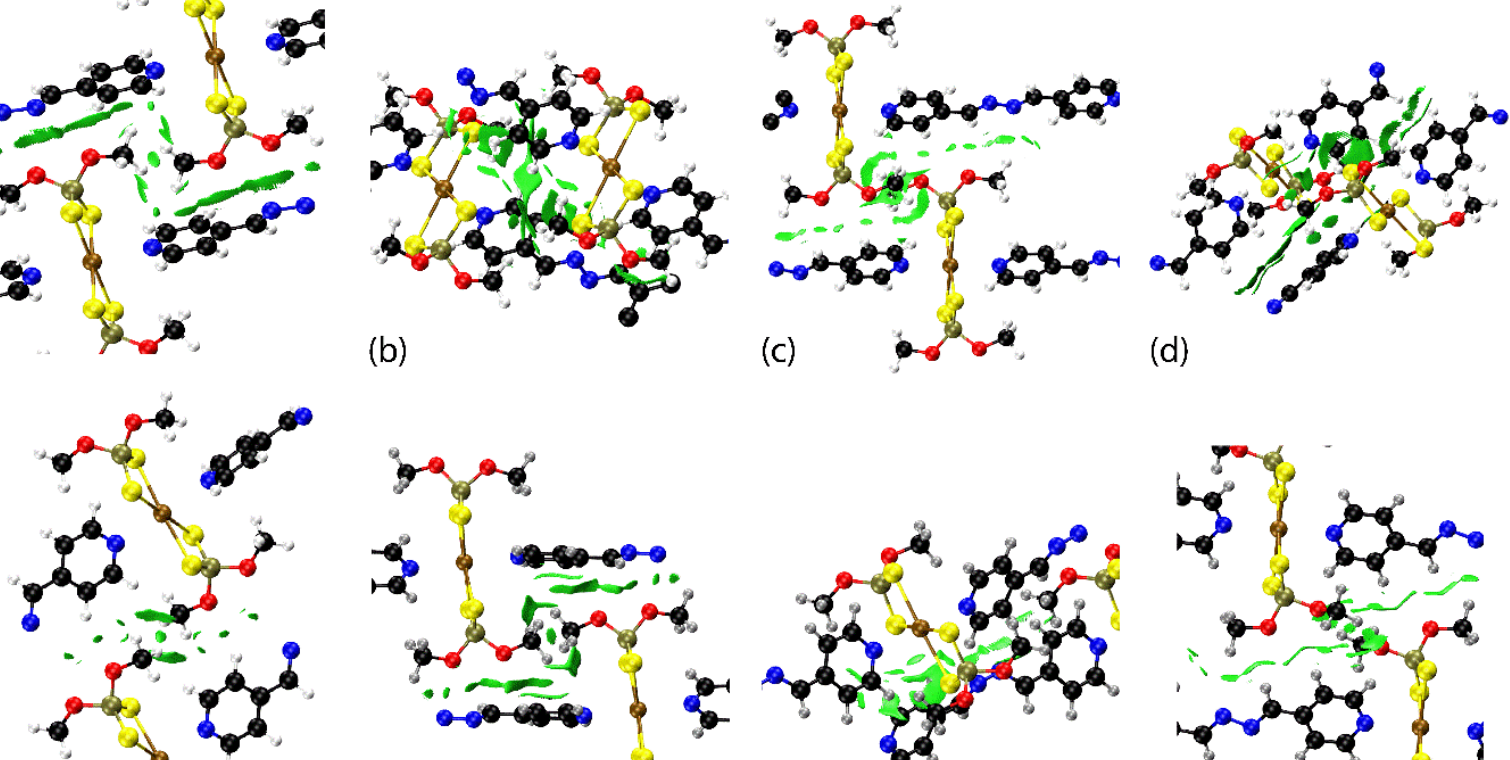

(e)
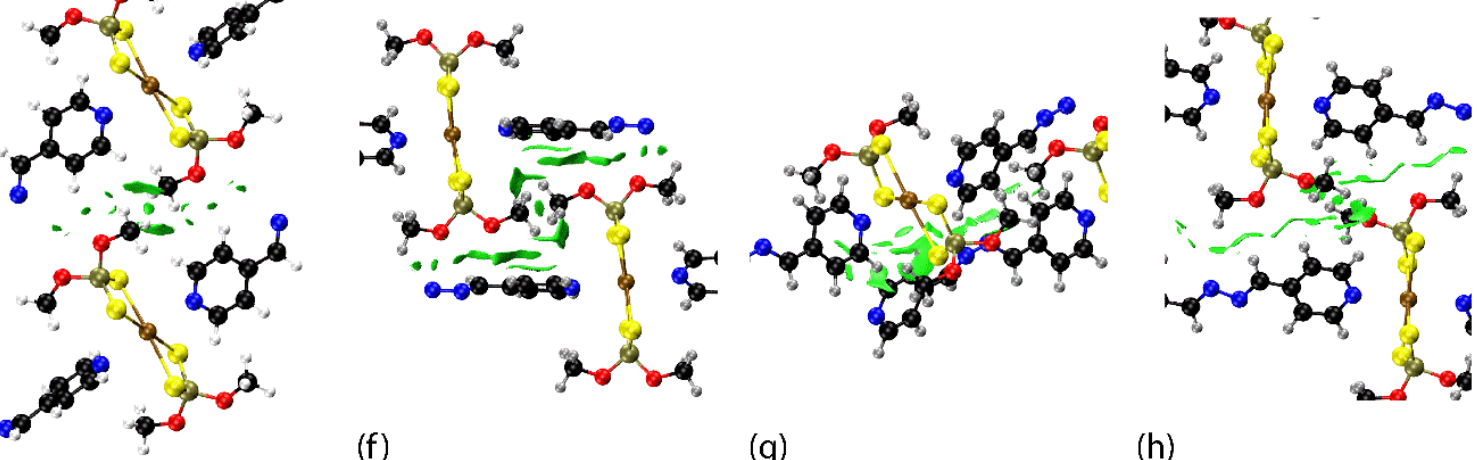

(f)

(g)

(h)

Figure 7. Images of non-covalent interaction plots for inter-chain interactions in (a)-(c) $\mathbf{1} \alpha$, (d)-(e) $\mathbf{1} \boldsymbol{\beta},(\mathrm{f})-(\mathrm{g}) \mathbf{1} \gamma$, and (h) $\mathbf{1} \boldsymbol{\delta}$, with the green regions indicating weakly attractive interactions (see text). 


\subsection{Hirshfeld surface analysis}

In order to analyze the molecular packing in more detail, an analysis of the calculated Hirshfeld surfaces was conducted employing Crystal Explorer $17^{59}$ and standard procedures, ${ }^{60}$ including those to differentiate between polymorphs. ${ }^{61}$ In each case, the calculations were performed on the $\left\{\mathrm{NC}(\mathrm{H}) \mathrm{C}_{5} \mathrm{H}_{4} \mathrm{NCd}\left[\mathrm{S}_{2} \mathrm{P}(\mathrm{OMe})_{2}\right]_{2} \mathrm{NC}_{5} \mathrm{H}_{4} \mathrm{C}(\mathrm{H}) \mathrm{N}\right\}$ repeat unit.

The Hirshfeld surface mapped over $d_{\text {norm }}$ for $1 \alpha$ is shown in Figure $8(a)$ where the red spots reflect the most prominent points of contact between chains to form the supramolecular layer illustrated in Figure 3(a). Table S2 lists additional interatomic contacts in the crystal of $\mathbf{1} \alpha$, namely $\mathrm{H}^{\cdots} \mathrm{H}$ and $\mathrm{S} \cdots \mathrm{H}$ contacts, these are indicated in the images of Figures $8(\mathrm{~b})$ and $8(\mathrm{c})$, respectively, and lead to a three-dimensional architecture. Similar considerations pertain to the polymorphs $\mathbf{1 \beta}-\mathbf{1 \delta}$, with geometric data given in Table S2 and images shown in Figure S2. In addition to weak $\mathrm{H}^{\cdots} \mathrm{H}$ and $\mathrm{S} \cdots \mathrm{H}$ points of contact between chains, the crystals of $\mathbf{1} \boldsymbol{\beta}-\mathbf{1} \boldsymbol{\delta}$ feature $\mathrm{O} \cdots \mathrm{C}$ and $\mathrm{N} \cdots \mathrm{H}(\mathbf{1} \boldsymbol{\beta}), \mathrm{O} \cdots \mathrm{C}$ and $\mathrm{O} \cdots \mathrm{H}(\mathbf{1} \gamma)$, and $\mathrm{S} \cdots \mathrm{C}, \mathrm{O} \cdots \mathrm{H}$, and $\mathrm{N}^{\cdots} \mathrm{H}(\mathbf{1} \boldsymbol{\delta})$ interatomic contacts, thereby differentiating the supramolecular association in the four polymorphs. 


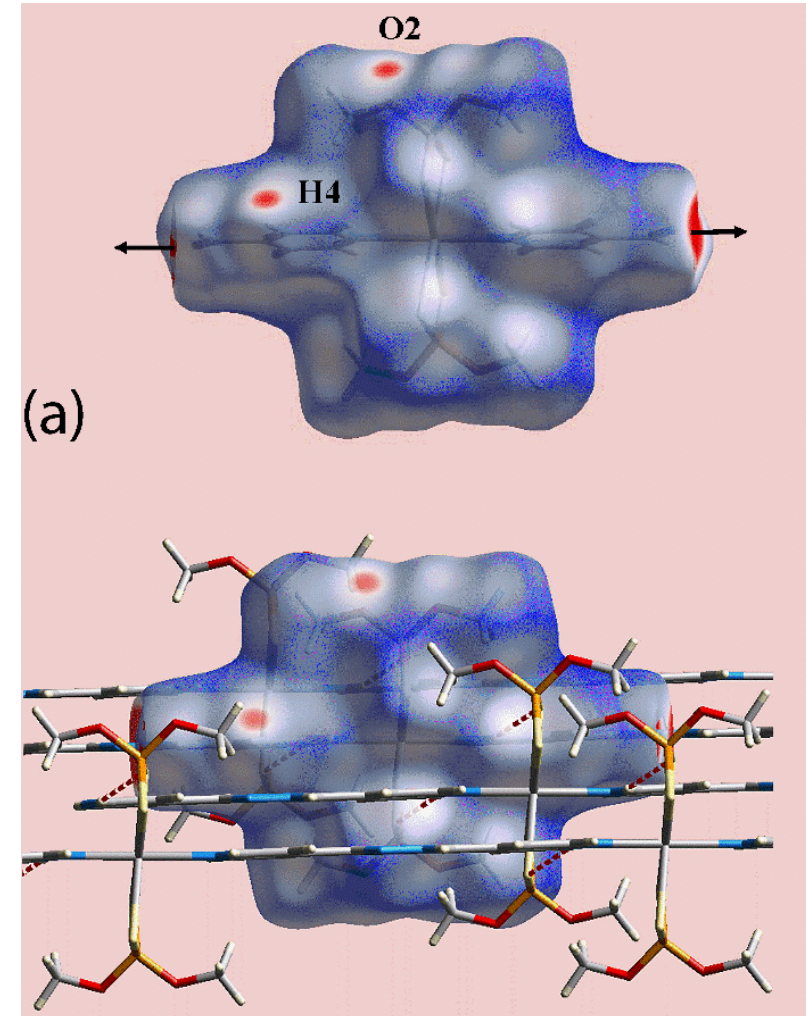

(b)

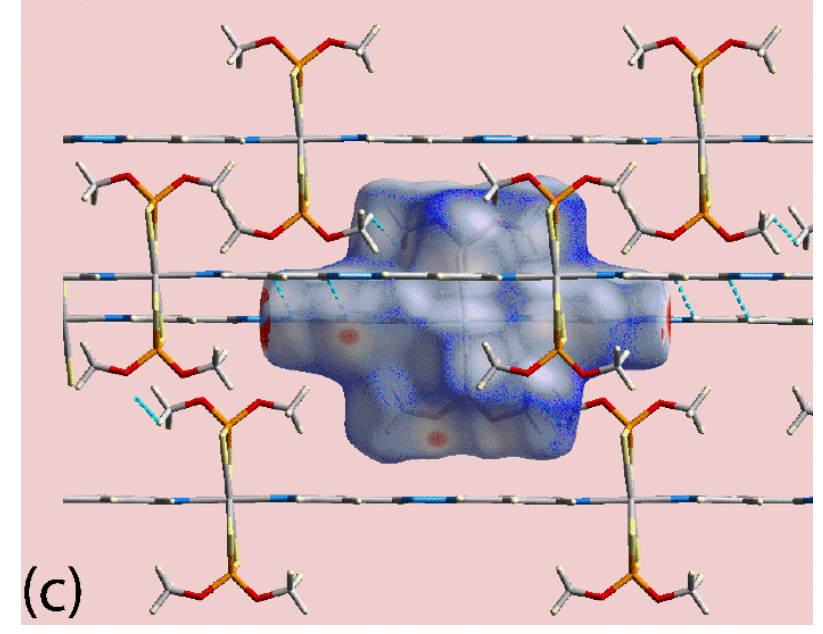

Figure 8. Images of the calculated Hirshfeld surfaces for the $1 \alpha$ form: (a)-(c) Hirshfeld surfaces mapped over $d_{\text {norm }}$ in the range in -0.181 to +1.541 arbitrary units highlighting interlayer, (b) $\mathrm{S} \cdots \mathrm{H} / \mathrm{H} \cdots \mathrm{S}$ contacts (red dashed lines), and (c) $\mathrm{H} \cdots \mathrm{H}$ contacts (sky-blue dashed lines).

The full two-dimensional, Figure 9, and delineated $\left(\mathrm{H}^{\cdots} \mathrm{H}, \mathrm{O} \cdots \mathrm{H} / \mathrm{H} \cdots \mathrm{O}, \mathrm{S} \cdots \mathrm{H} / \mathrm{H}^{\cdots} \mathrm{S}\right.$, $\mathrm{N}^{\cdots} \mathrm{H} / \mathrm{H}^{\cdots} \mathrm{N}$, and $\mathrm{N} \cdots \mathrm{N}$; Figure S4) fingerprint plots were also calculated for $\mathbf{1 \alpha}-\mathbf{1 \delta}$. As indicated above, the calculations were performed on the 
$\left\{\mathrm{NC}(\mathrm{H}) \mathrm{C}_{5} \mathrm{H}_{4} \mathrm{NCd}\left[\mathrm{S}_{2} \mathrm{P}(\mathrm{OMe})_{2}\right]_{2} \mathrm{NC}_{5} \mathrm{H}_{4} \mathrm{C}(\mathrm{H}) \mathrm{N}\right\}$ repeat unit so that sharp spikes in the plots are due to the N-N bonds, Figure S4(f). The different appearances of the full fingerprint plots reflect the distinct surface contacts at play in the respective crystals. Table S3 lists the percentage contributions to the surface contacts and this is represented graphically in Figure 10. The three main contributors to the Hirshfeld surfaces are $\mathrm{H}^{\cdots} \mathrm{H}$, ranging from $36.0(\mathbf{1} \gamma)$ to $39.8 \%(\mathbf{1 \alpha}), \mathrm{S}^{\cdots} \mathrm{H} / \mathrm{H}^{\cdots} \mathrm{S}$, ranging from $21.5(\mathbf{1 \delta})$ to $24.5 \%(\mathbf{1 \alpha})$, and $\mathrm{O} \cdots \mathrm{H} / \mathrm{H}^{\cdots} \mathrm{O}$, ranging from $10.8(\mathbf{1} \alpha)$ to $14.4 \%(\mathbf{1} \gamma)$. The next most significant percentage contributors to the Hirshfeld surface but at separations close to or beyond van der Waals distances are $\mathrm{N}^{\cdots} \mathrm{H} / \mathrm{H} \cdots \mathrm{N}$, ranging from $7.6(\mathbf{1 \beta})$ to $10.5 \%(\mathbf{1 \delta})$, and $\mathrm{C} \cdots \mathrm{H} / \mathrm{H} \cdots \mathrm{C}$, ranging from $6.3(\mathbf{1 \beta})$ to $10.9 \%(\mathbf{1 \delta})$, contacts. The crystals of $\mathbf{1} \beta(4.9 \%)$ and $\mathbf{1} \gamma(3.2 \%)$ feature inter-layer $\mathrm{C} \cdots \mathrm{O}$ contacts less than van der Waals separations between imine- and pyridyl-carbon atoms and methoxy-oxygen atoms. These result in forceps-like, short tips in the respective delineated $\mathrm{C} \cdots \mathrm{O} / \mathrm{O} \cdots \mathrm{C}$ fingerprint plots in Figures $\mathrm{S} 5(\mathrm{a})$ and $\mathrm{S} 5(\mathrm{~b})$. In the crystal of $\mathbf{1 \delta}, \mathrm{S} \cdots \mathrm{C} / \mathrm{C} \cdots \mathrm{S}$ contacts $(3.8 \%)$ involving dithiophosphate-sulfur and pyridyl-carbon atoms are noted and result in a pair of tong-shaped, short tips in the decomposed fingerprint plot of Figure S5(c).

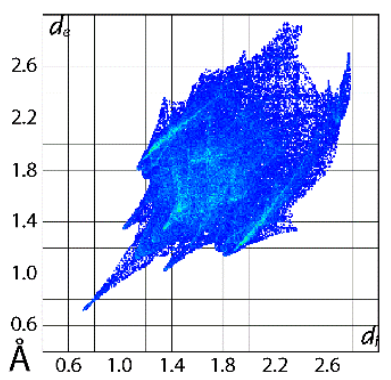

(a)

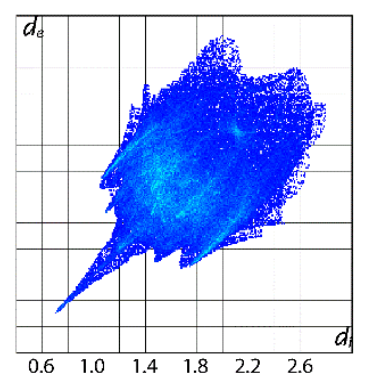

(b)

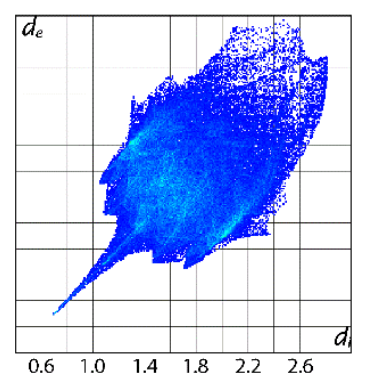

(c)

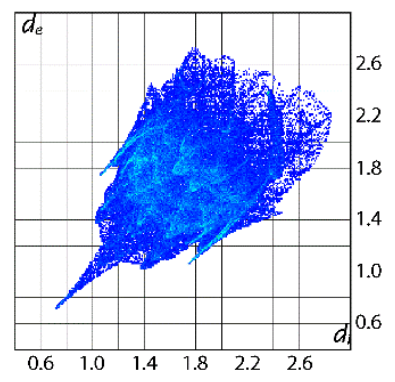

(d)

Figure 9. (a)-(d) A comparison of the full two-dimensional fingerprint plots for each of $1 \alpha-$ $\mathbf{1 \delta}$, respectively. 


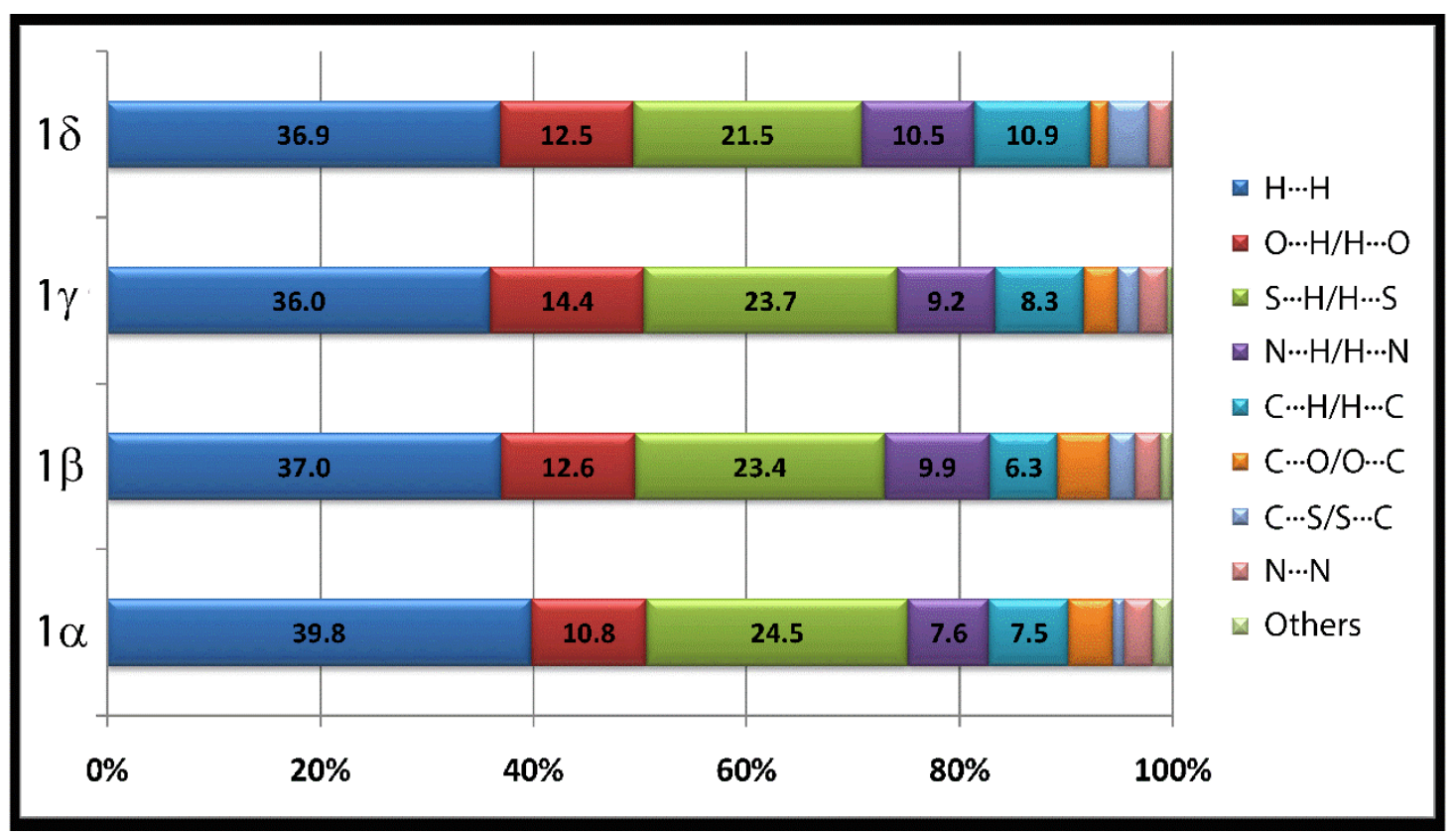

Figure 10. Bar graph illustrating the percentage contributions to the calculated Hirshfeld surfaces of $\mathbf{1} \alpha-\mathbf{1 \delta}$.

In the discussion of the molecular packing, it was noted that to a first approximation the packing in $\mathbf{1} \boldsymbol{\alpha}$ and $\mathbf{1 \delta}$, with flat 4-pyridine-aldazine bridges, resembled each other and this is borne out in the delineated fingerprint plots in Figures S4(b)-S4(e). In the same way, the decomposed fingerprint plots for $\mathbf{1} \boldsymbol{\beta}$ and $\mathbf{1} \boldsymbol{\gamma}$, with twisted 4-pyridine-aldazine bridges, resemble each other, Figures S4(b)-S4(e).

A recent development in Hirshfeld surface analysis has been to evaluate the surfaces about metal centers in coordination polymers. ${ }^{62}$ Such calculations can provide insight into metalligand interactions and differences in the coordination geometries between the polymorphs. In addition to differences in Cd-ligand bond lengths and angles, some non-trivial conformational differences in $\mathbf{1} \boldsymbol{\alpha}-\mathbf{1 \delta}$ are also apparent. As listed in Table $\mathrm{S} 1$, the four-membered $\mathrm{CdS}_{2} \mathrm{P}$ chelate rings exhibit deviations from planarity with the r.m.s. deviation of the four atoms ranging from $0.0315 \AA$, for the S1-chelate ring in $\mathbf{1} \gamma$, to $0.1428 \AA$ for both chelate rings in $\mathbf{1} \boldsymbol{\delta}$. 
The dihedral angles between the $\mathrm{PS}_{2}$ planes vary from $0^{\circ}$ in $\mathbf{1} \boldsymbol{\alpha}$ and $\mathbf{1} \boldsymbol{\delta}$, where the cadmium atom lies on a center of inversion, to $17.618(19)^{\circ}$ in $\mathbf{1} \beta$. Finally, the distances the cadmium atoms lie out of the planes through the $\mathrm{PS}_{2}$ atoms vary markedly. Thus, for $\mathbf{1} \alpha$ the displacement from each $\mathrm{PS}_{2}$ plane is $0.357(2) \AA$ but, for $\mathbf{1} \boldsymbol{\delta}$, this increases to $0.8665(17) \AA$. In $\mathbf{1} \boldsymbol{\beta}$ and $\mathbf{1} \boldsymbol{\gamma}$, the displacements are generally smaller, ranging from $0.1906(16)$ to $0.4044(15) \AA$ in $\mathbf{1 \delta}$. The different bond lengths and geometries around the cadmium atoms lead to different shapes of the calculated Hirshfeld surfaces.

The $\mathrm{Cd}-\mathrm{N}$ coordination bonds on both the sides of the Hirshfeld surface mapped over $d_{\text {norm }}$ for $\mathbf{1} \alpha$, Figure 11(a) and $\mathbf{1} \boldsymbol{\beta}-\mathbf{1 \delta}$, Figure S6, appears as the bright-red spots perpendicular to the $\mathrm{Cd}-\mathrm{N}$ bond direction. The strength of the $\mathrm{Cd}-\mathrm{N}$ bonds are also evident as the rectangular orange spots and the green flat regions on the Hirshfeld surface mapped with shape-index (S) and over curvedness (C), respectively, shown in Figures 11(b) and 11(c) for 1a, and Figures S7 and S8 for $\mathbf{1} \boldsymbol{\beta}-\mathbf{1 \delta}$. 


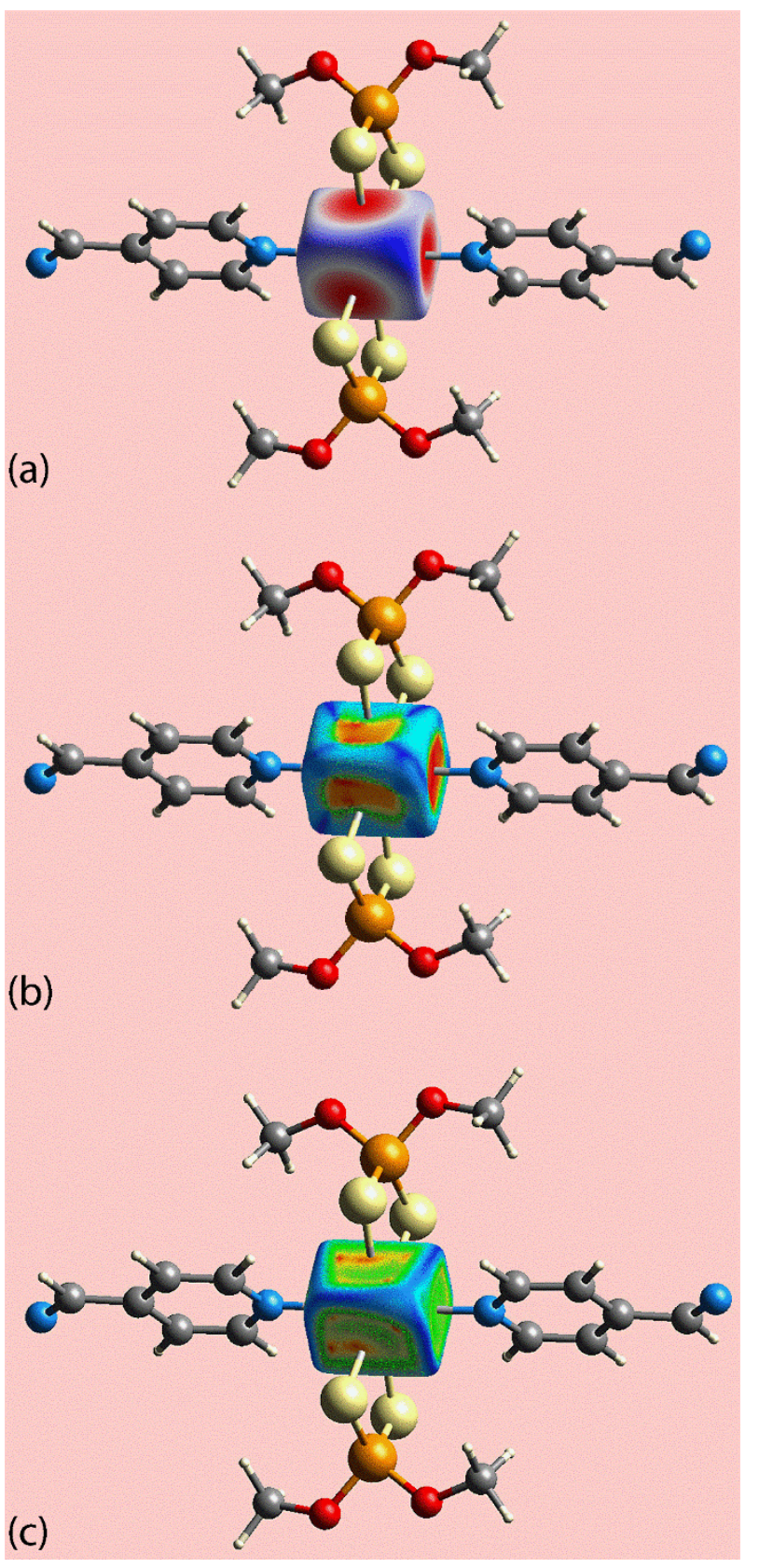

Figure 11. Views of Hirshfeld surfaces for the cadmium center in $1 \alpha$ along mapped over (a) $d$ norm in the range -0.4 to $+0.9 \AA$, (b) the shape-index $(\mathrm{S})$ in the range -1.0 to +1.0 arbitrary units and, (c) the curvedness $(\mathrm{C})$ in the range -4.0 to +0.4 arbitrary units.

Similar trends to those just described are evident for the $\mathrm{Cd}-\mathrm{S}$ bonds. The orange patches of irregular shape surrounded by yellow regions on the shape-index mapped Hirshfeld surfaces about the cadmium centers facing the sulfur atoms in Figure 11(b) for $\mathbf{1} \boldsymbol{\alpha}$ (Figure S7 for $\mathbf{1} \boldsymbol{\beta}-$ 
18) are indicative of differences in the $\mathrm{Cd}-\mathrm{S}$ bond lengths. It is also observed from these images for $\mathbf{1} \boldsymbol{\alpha}-\mathbf{1} \delta$ that the sulfur atoms link the cadmium centers through the regions outside the orange patches on the surfaces indicating deviations of the $\mathrm{Cd}-\mathrm{S}$ bonds from the normal of the surfaces. The small red regions on the Hirshfeld surfaces mapped over curvedness in Figure 11(c) for $\mathbf{1} \boldsymbol{\alpha}$ (Figure S8 for $\mathbf{1} \boldsymbol{\beta}-\mathbf{1 \delta}$ ) reflect the nature and strength of the $\mathrm{Cd}-\mathrm{S}$ bonds.

The cadmium coordination environments are also rationalized in the fingerprint plots considering only the Hirshfeld surfaces about central atom for each of the polymorphs, Figure 12. It is evident in all fingerprint plots that the long red spikes at $d_{\mathrm{e}}+d_{\mathrm{i}} \sim 2.4 \AA$ indicate $\mathrm{Cd}-$ $\mathrm{N}$ bonds whereas the red pencil tips at $d_{\mathrm{e}}+d_{\mathrm{i}}<2.7 \AA$ are due to the $\mathrm{Cd}-\mathrm{S}$ bonds. The subtle differences in modes of association by the sulfur atoms, Table S1, are reflected in the distinct and asymmetric distribution of points in the upper portions of the plots in Figure 12.

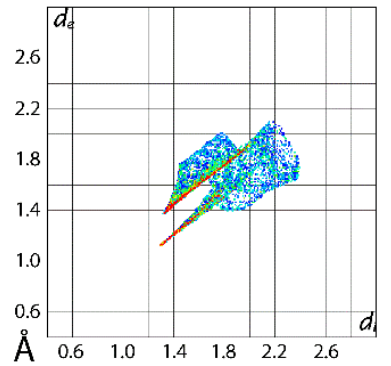

(a)

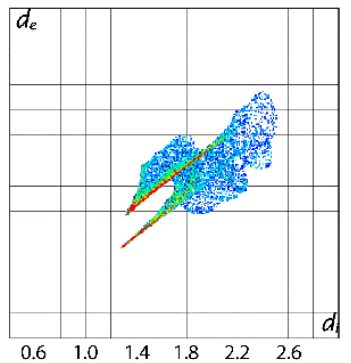

(b)

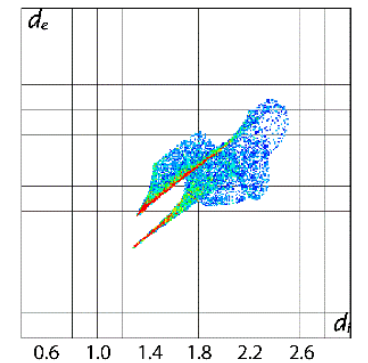

(c)

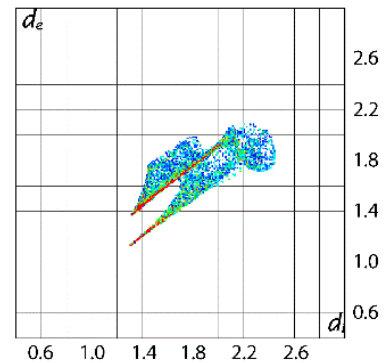

(d)

Figure 12. (a)-(d) A comparison of the two-dimensional fingerprint plots calculated for the cadmium center only, for each of $\mathbf{1} \boldsymbol{\alpha}-\mathbf{1 \delta}$, respectively.

\subsection{Powder X-ray Diffraction (PXRD) Experiments}

The room temperature PXRD trace measured at room temperature (293 K) corresponded to $1 \boldsymbol{\alpha}$, while that measured at $100 \mathrm{~K}$ is consistent with the presence of $\mathbf{1} \beta$, Figure S9; no evidence for either $\mathbf{1} \gamma$ or $\mathbf{1} \boldsymbol{\delta}$ was found in any of the PXRD patterns. A variable- temperature PXRD study was conducted whereby the bulk material was cooled from 293 to $100 \mathrm{~K}$ in $10^{\circ}$ steps. Figure 
13(a) shows excerpts of the full set of traces shown in Figure S10(a). In the cooling cycle, $1 \alpha$ starting converting to $\mathbf{1} \beta$ below $183 \mathrm{~K}$ with complete conversion to $1 \beta$ at $123 \mathrm{~K}$, i.e., over a $60^{\circ}$ temperature range. Then the sample was heated in $10^{\circ}$ steps, Figure $13(\mathrm{~b})$ and Figure $\mathrm{S} 10(\mathrm{~b})$. This resulted in conversion of $\mathbf{1} \boldsymbol{\beta}$ to $\mathbf{1} \boldsymbol{\alpha}$ with onset at $213 \mathrm{~K}$ with complete conversion by 233 $\mathrm{K}$, i.e., over a $20^{\circ}$ range. The same observations were apparent in a second cycle of heating/cooling.

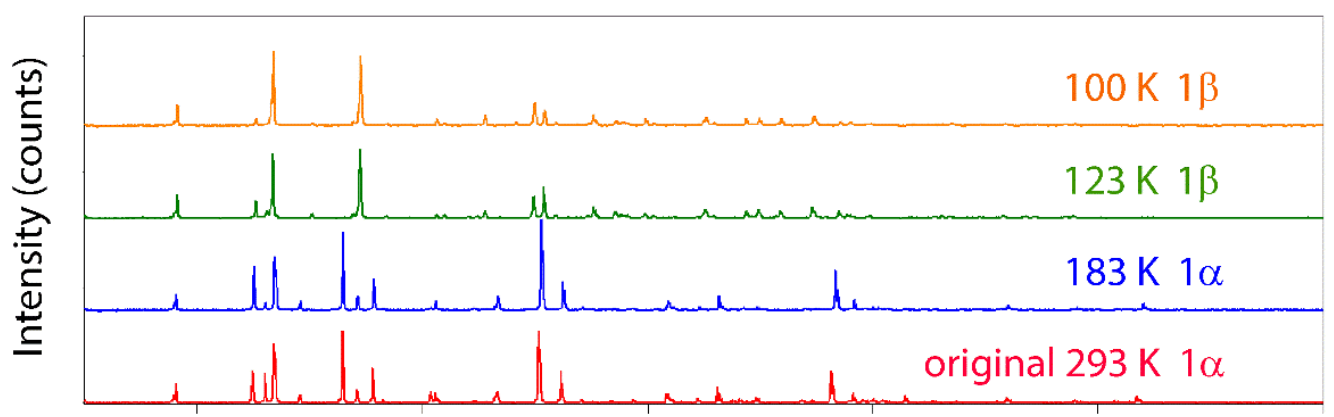

(a)

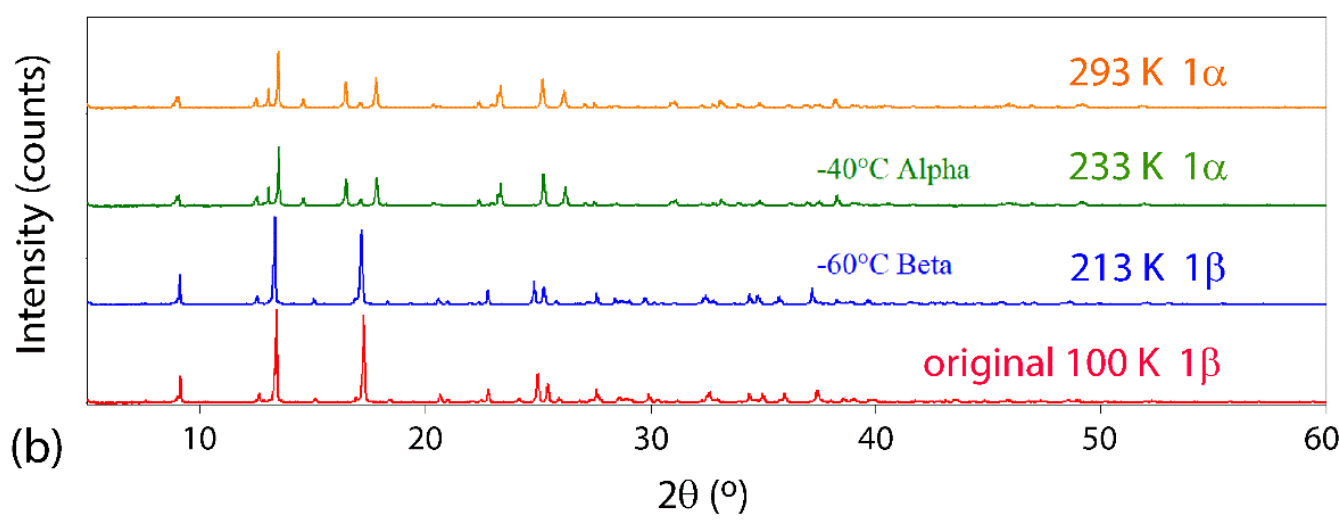

Figure 13. Variable temperature powder X-ray diffraction patterns: (a) cooling $1 \boldsymbol{\alpha}$ from 293 $\mathrm{K}$ to $100 \mathrm{~K}$ resulting in complete conversion to $\mathbf{1 \beta}$ between 183 and $123 \mathrm{~K}$ and (b) heating $\mathbf{1 \beta}$ from $100 \mathrm{~K}$ to $293 \mathrm{~K}$ resulting in complete conversion to $1 \alpha$ between 233 and $213 \mathrm{~K}$.

\subsection{Thermal Studies}

Three cycles of cooling to $100 \mathrm{~K}$ and heating to $298 \mathrm{~K}$ were conducted on the bulk material, Figure 14. These revealed the reversible phase change between $\mathbf{1} \alpha$ and $\mathbf{1} \boldsymbol{\beta}$, with no evidence 
of a phase change to either $\mathbf{1} \boldsymbol{\gamma}$ or $\mathbf{1} \boldsymbol{\delta}$; no special features were observed in DSC measurements conducted up to $20 \mathrm{~K}$ from the temperature of decomposition. The temperature of phase change from $1 \alpha$ to $1 \beta$ in the first cycle occurred at $243 \mathrm{~K}$ and back to $1 \alpha$ at $279 \mathrm{~K}$. For the second and third cycles, the $1 \alpha$ to $1 \beta$ phase change occurred at $253 \mathrm{~K}$ with the reverse phase change occurring consistently at $279 \mathrm{~K}$. This disparity in temperature is explained in terms of "thermal history". ${ }^{63}$

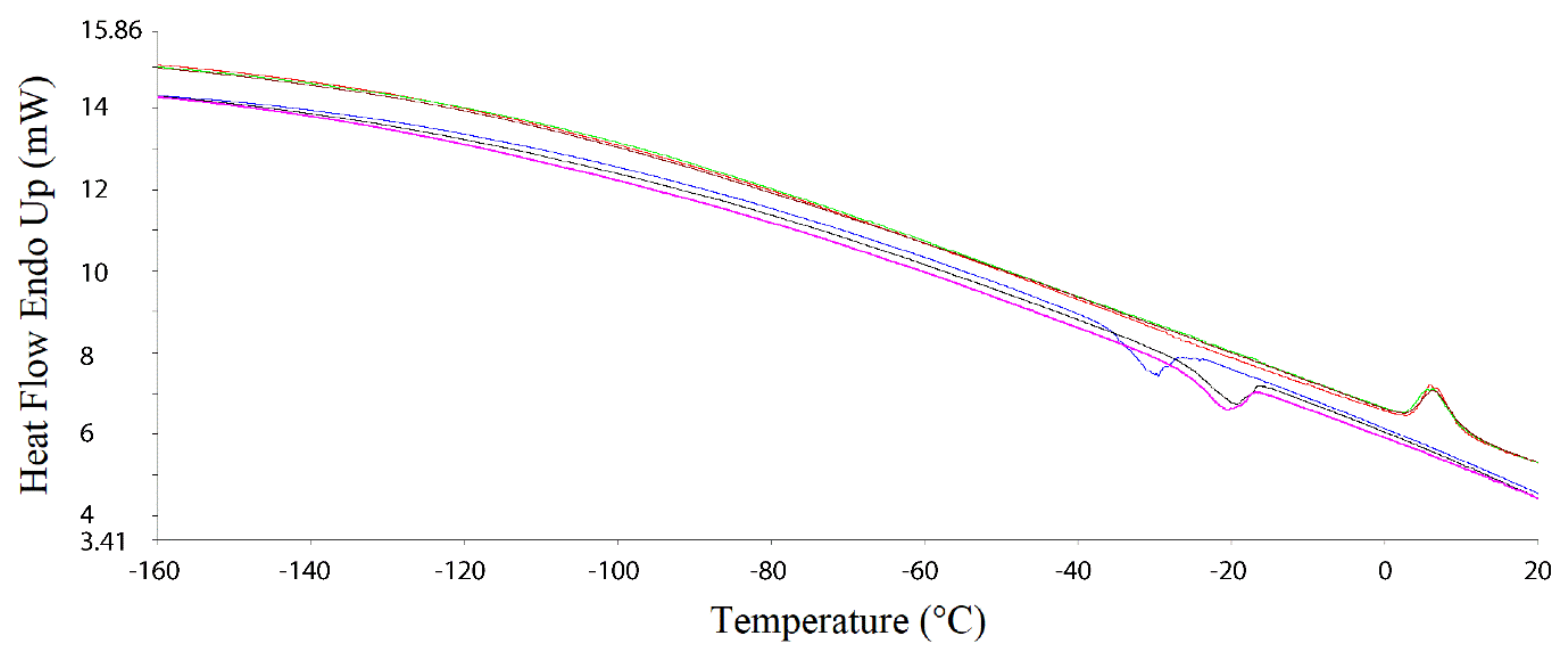

Figure 14. Three cycles of DSC traces performed in the range 293 to $100 \mathrm{~K}$ and back showing a reversible phase change between $\mathbf{1} \boldsymbol{\alpha}$ and $\mathbf{1} \boldsymbol{\beta}$. The first cooling $(243 \mathrm{~K}) /$ heating $(279 \mathrm{~K})$ cycle is shown in blue $(254 \mathrm{~K}) / \mathrm{red}(279 \mathrm{~K})$, the second in black $(253 \mathrm{~K}) /$ green $(279 \mathrm{~K})$, and the third in purple/maroon.

\subsection{Single-Crystal-Single-Crystal Phase Changes}

The experiments on the bulk sample of $1 \alpha$ provided evidence of a reversible phase change between $1 \alpha$ and $1 \beta$. Thus, variable temperature experiments were conducted on single crystals with the results summarized in Figure 15; unit cell data for the described phase changes are included in Table S5. Based on the DSC experiment, unit cell data were collected at temperatures at either side of the identified phase transformations. Cooling $1 \alpha$ at the rate of 6 
${ }^{\circ} \mathrm{C} / \mathrm{min}$ resulted in $100 \%$ conversion to $\mathbf{1} \beta$ at $233 \mathrm{~K}$. Further cooling did not result in a phase change. Heating $1 \boldsymbol{\beta}$ from $100 \mathrm{~K}$ resulted in complete conversion to $1 \boldsymbol{\alpha}$ by $293 \mathrm{~K}$. Attention was then directed towards evaluating the phase changes for $\mathbf{1} \gamma$ and $\mathbf{1} \boldsymbol{\delta}$. Out of about 20 samples placed under the cold stream at $100 \mathrm{~K}$, about one proved to be $\mathbf{1} \gamma$ and another $\mathbf{1 \delta}$. When $\mathbf{1} \boldsymbol{\gamma}$ was heated and unit cells measured every $10 \mathrm{~K}$, a phase change to $\mathbf{1} \boldsymbol{\beta}$ occurred between 120 and $130 \mathrm{~K}$. A second phase change from $\mathbf{1} \boldsymbol{\beta}$ to $1 \boldsymbol{\alpha}$ occurred between 270 and $280 \mathrm{~K}$. Subsequent cooling only gave evidence for the phase change to $\mathbf{1} \boldsymbol{\beta}$. In analogous experiments with $1 \delta$, a phase change to $1 \beta$ occurred between 140 and $150 \mathrm{~K}$ with a subsequent phase change to $1 \boldsymbol{\alpha}$ between 270 and $280 \mathrm{~K}$; again, cooling only yielded $\mathbf{1} \boldsymbol{\beta}$.

\section{Cooling}

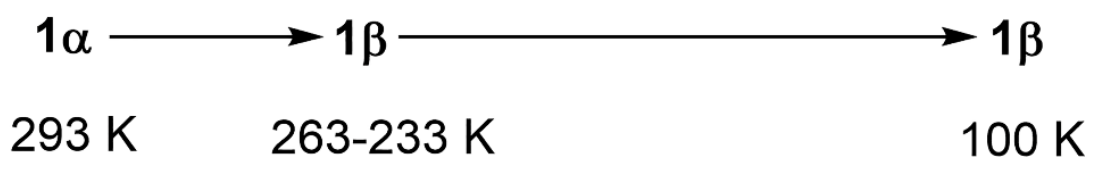

\section{Heating}

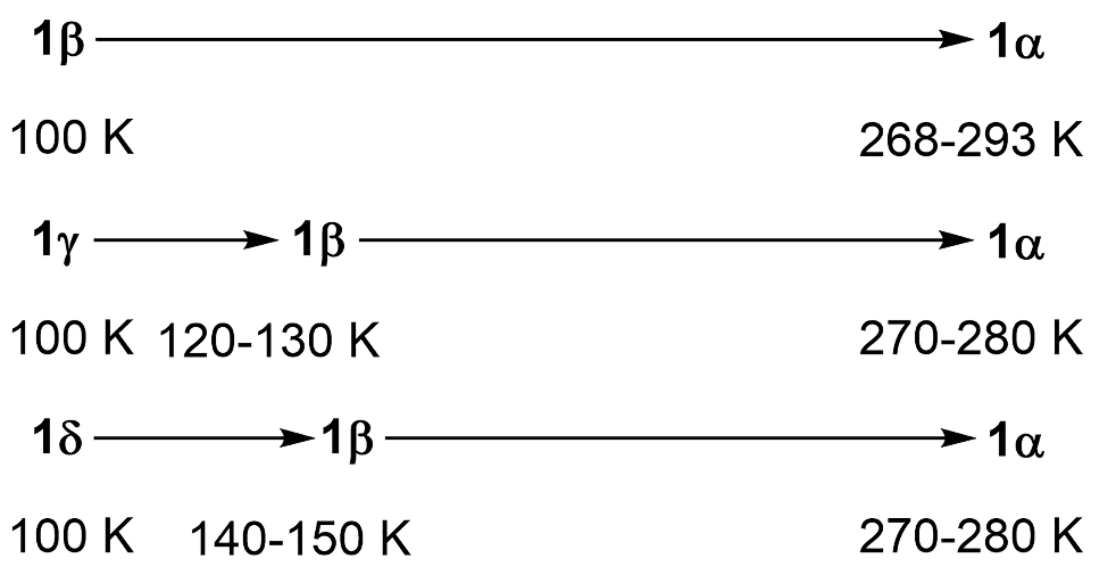

Figure 15. Summary of the single-crystal-single-crystal phase changes for $\mathbf{1} \boldsymbol{\alpha}-\mathbf{1 \delta}$ as determined by unit cell determinations. 
As mentioned in the Introduction, the lattice energies for different polymorphs are often very close to each other. This proved true for lattice energies, defined here as the negative energy required to pull the crystal apart, calculated for $\mathbf{1 \alpha}-\mathbf{1 \delta}$. The thermodynamically most stable polymorph is $1 \alpha(0 \mathrm{kcal} / \mathrm{mol})$ and the differences in lattice energy for $\mathbf{1} \boldsymbol{\beta}(1.52 \mathrm{kcal} / \mathrm{mol})$, $\mathbf{1} \gamma(2.62 \mathrm{kcal} / \mathrm{mol})$ and $\mathbf{1} \boldsymbol{\delta}(1.97 \mathrm{kcal} / \mathrm{mol})$ indicate that $\mathbf{1} \boldsymbol{\beta}$ is the next most stable polymorph and $1 \boldsymbol{\gamma}$ to be the least stable polymorph.

A gratifying trend between phase transformations and the calculated lattice energies is apparent. The least stable polymorphs, $\mathbf{1} \boldsymbol{\gamma}$ and $\mathbf{1} \boldsymbol{\delta}$, each converts to $\mathbf{1} \boldsymbol{\beta}$ and $\mathbf{1} \boldsymbol{\beta}$, in turn, converts to $\mathbf{1} \alpha$, in accord with the calculations. Further, the least stable polymorph $\mathbf{1} \gamma$, converts to $\mathbf{1} \boldsymbol{\beta}$ at a lower temperature than the next least stable polymorph, $\mathbf{1} \boldsymbol{\delta}$.

To a first approximation, forms $\mathbf{1} \boldsymbol{\alpha}$ and $\mathbf{1} \boldsymbol{\delta}$, with comparable twists in their 4-pyridinealdazine bridges, exhibit similar supramolecular layers in their crystals. Relatively minor differences are noted in the unit cell parameters in their triclinic, $P \overline{1}$ unit cells with $Z=1$, Table 1. Similarly, $\mathbf{1} \boldsymbol{\beta}$ and $\mathbf{1} \boldsymbol{\gamma}$, with planar 4-pyridine-aldazine bridges, exhibit similar supramolecular layers in their crystals but no simple relationship exists between their monoclinic, $C 2 / c$ with $Z=8(\mathbf{1} \boldsymbol{\beta})$ and triclinic, $P \overline{1}$ with $Z=2(\mathbf{1} \gamma)$ unit cells. Having data recorded at $100 \mathrm{~K}$, it is legitimate to compare the crystal characteristics of $\mathbf{1} \boldsymbol{\beta}-\mathbf{1 \delta} .^{64}$ The calculated densities of the crystals increase from $1.723(\mathbf{1} \beta), 1.731(\mathbf{1} \gamma)$, and $1.743 \mathrm{~g} / \mathrm{cm}^{3}(\mathbf{1} \boldsymbol{\delta})$, Table 1. These trends are reflected in the calculated packing indices, ${ }^{46}$ i.e., 68.9, 69.2, and $69.7 \%$, respectively.

\section{CONCLUSION}

Four polymorphs have been revealed for the one-dimensional, linear coordination polymer $\left\{\mathrm{Cd}\left[\mathrm{S}_{2} \mathrm{P}(\mathrm{OMe})_{2}\right]_{2}(4 \text {-pyridine-aldazine })\right\}_{\mathrm{n}}$ (1); each exhibits distinctive patterns in the 
molecular packing. Two forms, $\mathbf{1} \alpha$ and $\mathbf{1} \beta$, exhibit reversible single-crystal-single-crystal phase changes as well in powdered form. Forms $\mathbf{1} \boldsymbol{\gamma}$ and $\mathbf{1} \boldsymbol{\delta}$ are only observed when $\mathbf{1}$ is snap frozen at $100 \mathrm{~K}$ but most of time $\mathbf{1} \boldsymbol{\beta}$ is observed under these conditions. Heating $\mathbf{1} \boldsymbol{\gamma}$ and $\mathbf{1} \boldsymbol{\delta}$ results in a transformation to $\mathbf{1} \beta$ and then to $1 \alpha$. Cooling $1 \alpha$, results in $1 \beta$ with no evidence of a further phase change to either of $\mathbf{1} \boldsymbol{\gamma}$ or $\mathbf{1 \delta}$ upon further cooling, suggesting $\mathbf{1} \boldsymbol{\gamma}$ or $\mathbf{1 \delta}$ are metastable polymorphs.

\section{ASSOCIATED CONTENT}

Supporting Information Available. Crystallographic data for $\mathbf{1} \alpha-1 \delta$ in CIF format, geometric data, intermolecular interaction distances, Hirshfeld surface images, DSC, and PXRD patterns. This material is available free of charge via the Internet at http://pubs.acs.org.

\section{Accession Codes}

CCDC 1978733-1978736 contain the supplementary crystallographic data for this paper. These data can be obtained free of charge via www.ccdc.cam.ac.uk/data_request/cif, or by emailing data_request@ecdc.cam.ac.uk or by contacting The Cambridge Crystallographic Data Centre, 12 Union Road, Cambridge CB2 1EZ, UK; fax: +44 1223336033.

\section{AUTHOR INFORMATION}

\section{Corresponding Author}

*E-mail: edwardt@sunway.edu.my

\section{ORCHID}

Edward R.T. Tiekink: 0000-0003-1401-1520 


\section{Notes}

The authors declare no competing financial interest.

\section{ACKNOWLEDGMENTS}

Crystallographic research at Sunway University is supported by Sunway University Sdn Bhd (Grant no. STR-RCTR-RCCM-001-2019). A.O.R acknowledges the Spanish Government for a Ramón y Cajal fellowship (RyC-2016-20301) and for financial support (projects PGC2018097520-A-100 and RED2018-102612T). 


\section{REFERENCES}

(1) Bernstein, J. Polymorphism in Molecular Crystals; Clarendon: Oxford, 2002.

(2) Brittain, H. G. Polymorphism in Pharmaceutical Solids; $2^{\text {nd }}$ edn, Informa Healthcare USA: New York, 2009.

(3) Gentili, D.; Gazzano, M.; Melucci, M.; Jones, D.; Cavallini, M. Polymorphism as an additional functionality of materials for technological applications at surfaces and interfaces. Chem. Soc. Rev. 2019, 48, 2502-2517.

(4) Cruz-Cabeza, A. J.; Reutzel-Edens, S. M.; Bernstein, J. Facts and fictions about polymorphism. Chem. Soc. Rev. 2015, 44, 8619-8635.

(5) Bauer, J.; Spanton, S.; Henry, R.; Quick, J.; Dziki, W.; Porter, W.; Morris, J. Ritonavir: An example of conformational polymorphism. Pharm. Res. 2001, 43, 859-866.

(6) Bučar, D.-K.; Lancaster, R. W.; Bernstein, J. Disappearing polymorphs revisited. Angew. Chem., Int. Ed. 2015, 54, 6972-6993.

(7) Neumann, M. A.; van de Streek, J. How many ritonavir cases are there still out there? Faraday Discuss. 2018, 211, 441-458.

(8) Price, S. L.; Braun, D. E.; Reutzel-Edens, S. M. Can computed crystal energy landscapes help understand pharmaceutical solids? Chem. Commun. 2016, 52, 7065-7077.

(9) Price, S. L. Is zeroth order crystal structure prediction (CSP_0) coming to maturity? What should we aim for in an ideal crystal structure prediction code? Faraday Discuss. 2018, 211,9-30.

(10) Bhardwaj, R. M.; McMahon, J. A.; Nyman, J.; Price, L. S.; Konar, S.; Oswald, I. D. H.; Pulham, C. R.; Price, S. L.; Reutzel-Edens, S. M. A prolific solvate former, Galunisertib, under the pressure of crystal structure prediction, produces ten diverse polymorphs. $J$. Am. Chem. Soc. 2019, 141, 13887-13897. 
(11) Haleblian, J.; McCrone, W. Pharmaceutical applications of polymorphism. J. Pharm. Sci. 1969, 58, 911-929.

(12) Gavezzotti, A.; Filippini, G. Polymorphic forms of organic crystals at room conditions: Thermodynamic and structural implications. J. Am. Chem. Soc. 1995, 117, 12299-12305.

(13) Nyman, J.; Day, G. M. Static and lattice vibrational energy differences between polymorphs. CrystEngComm, 2015, 17, 5154-5165.

(14) Naumov, P.; Chizhik, S.; Panda, M. K.; Nath, N. K.; Boldyreva, Mechanically responsive molecular crystals. Chem. Rev. 2015, 115, 12440-12490.

(15) Donoshita, M.; Hayashi, M.; Ikeda, R.; Yoshida, Y.; Morikawa, S.; Sugimoto, K.; Kitagawa, H. Drastic rearrangement of self-assembled hydrogen-bonded tapes in a molecular crystal. Chem. Commun. 2018, 54, 8571-8594.

(16) Schmidt, G. M. J. Photodimerization in the solid state. Pure Appl. Chem. 1971, 27, 647678.

(17) Nakasuji, K.; Sasaki, M.; Kotani, T.; Murafa, I.; Enoki, T.; Imaeda, K.; Inokuchi, H.; Kawamoto, A.; Tanaka, Methylthio- and ethanediyldithio-substituted 1,6-dithiapyrenes and their charge-transfer complexes: new organic molecular metals. J. Am. Chem. Soc. 1987, 109, 6970-6975.

(18) Yu, L. Polymorphism in molecular solids: An extraordinary system of red, orange, and yellow crystals. Acc. Chem. Res. 2010, 43, 1257-1266.

(19) Saha, S.; Desiraju, G. R. Trimorphs of 4-bromophenyl 4-bromobenzoate. Elastic, brittle, plastic. Chem. Commun. 2018, 54, 6348-6351.

(20) Larsen, F. K. Diffraction studies of crystals at low temperatures - crystallography below 77 K. Acta Crystallogr. B, 1994, 51, 468-482.

(21) Myles, D. A. A., Dauvergne, F.; Blakeley, M. P.; Meilleur, F. Neutron protein crystallography at ultra-low $(<15 \mathrm{~K})$ temperatures. J. Appl. Cryst. 2012, 45, 686-692. 
(22) Goeta, A. E.; Howard, J. A. K. Low temperature single crystal X-ray diffraction: advantages, instrumentation and applications. Chem. Soc. Rev. 2004, 33 490-500.

(23) Sztylko, M.; Malinska, M.; Petricek, V.; Gutmann, M. J.; Hoser, A. A. How accurate do x-ray data need to be to obtain a reliable order of stability for polymorphs? The case study of p-hydroxyacetophenone polymorphs. Cryst. Growth Des. 2019, 19, 5132-5141.

(24) Thompson, A. L. Chemical Crystallography: when are 'bad data' 'good data'? Crystallogr. Rev. 2019, 25, 3-53.

(25) Harada, J.; Ogawa, K. X-ray diffraction analysis of nonequilibrium states in crystals: Observation of an unstable conformer in flash-cooled crystals. J. Am. Chem. Soc. 2004, $126,3539-3544$.

(26) Crawford, A. W.; Groeneman, R. H.; Unruh, D. K.; Hutchins, K. M. Cooling-rate dependent single-crystal-to-single-crystal phase transition in an organic co-crystal. Chem. Commun. 2019, 55, 3258-3261.

(27) Tiekink, E. R. T. Molecular architecture and supramolecular association in the zinc-triad 1,1-dithiolates. Steric control as a design element in crystal engineering? CrystEngComm, 2003, 5, 101-113.

(28) Tan, Y. S.; Sudlow, A. L.; Molloy, K. C.; Morishima, Y.; Fujisawa, K.; Jackson, W. J.; Henderson, W.; Halim, S. N. Bt. A.; Ng, S. W.; Tiekink, E. R. T. Supramolecular isomerism in a cadmium bis( $N$-hydroxyethyl, $N$-isopropyldithiocarbamate) compound: physiochemical characterization of ball $(n=2)$ and chain $(n=\infty)$ forms of $\left\{\mathrm{Cd}\left[\mathrm{S}_{2} \mathrm{CN}(\mathrm{iPr}) \mathrm{CH}_{2} \mathrm{CH}_{2} \mathrm{OH}\right]_{2} \cdot \text { solvent }\right\}_{\text {n. }}$. Cryst. Growth Des. 2013, 13, 3046-3056.

(29) Ahmad, J.; How, F. N.-F.; Halim, S. N. A.; Jotani, M. M.; Lee, S. M.; Tiekink, E. R. T. A new structural motif for cadmium dithiocarbamates: crystal structures and Hirshfeld surface analyses of homoleptic zinc and cadmium morpholine dithiocarbamates. $Z$. Kristallogr. Cryst. Mater. 2019, 234, 341-349. 
(30) Tiekink, E. R. T. Exploring the topological landscape exhibited by binary zinc-triad 1,1dithiolates. Crystals, 2018, 8, 292.

(31) Lai, C. S.; Lim, Y. X.; Yap, T. C.; Tiekink, E. R. T. Molecular paving with zinc thiolates CrystEngComm, 2002, 4, 596-600.

(32) Koh, Y. W.; Lai, C. S.; Du, A. Y.; Tiekink, E. R. T.; Loh, K. P. Growth of bismuth sulfide nanowire using bismuth trisxanthate single source precursors. Chem. Mater. 2003, 15, $4544-4554$.

(33) Lai, C. S.; Liu, S.; Tiekink, E. R. T. Steric control over polymer formation and topology in adducts of zinc dithiophosphate formed with bridging bipyridine ligands. CrystEngComm, 2004, 6, 221-226.

(34) Lai, C. S.; Tiekink, E. R. T. Engineering polymers with variable topology - bipyridine adducts of cadmium dithiophosphates. CrystEngComm, 2004, 6, 593-605.

(35) Poplaukhin, P.; Tiekink, E. R. T. Interwoven coordination polymers sustained by tautomeric forms of the bridging ligand. CrystEngComm, 2010, 12, 1302-1306.

(36) Tan, Y. S.; Halim, S. N. A.; Tiekink, E. R. T. Exploring the crystallization landscape of cadmium bis(N-hydroxyethyl, $\quad$ N-isopropyl-dithiocarbamate), $\mathrm{Cd}\left[\mathrm{S}_{2} \mathrm{CN}(\mathrm{iPr}) \mathrm{CH}_{2} \mathrm{CH}_{2} \mathrm{OH}\right]$ 2. Z. Kristallogr. Cryst. Mater. 2016, 231, 113-126.

(37) Tiekink, E. R. T. Perplexing coordination behaviour of potentially bridging bipyridyltype ligands in the coordination chemistry of zinc and cadmium 1,1-dithiolate compounds. Crystals, 2018, $8,18$.

(38) Tan, Y. S.; Chun, H. Z.; Jotani, M. M.; Tiekink, E. R. T. Steric control of supramolecular association in structures of $\mathrm{Zn}\left(\mathrm{S}_{2} \mathrm{COR}\right)_{2}$ with $\mathrm{N}, \mathrm{N}^{\prime}$-bis(pyridin-4-ylmethyl)oxalamide. $Z$. Kristallogr. Cryst. Mater. 2019, 234, 165-175.

(39) Leong, W. L.; Vittal, J. J. One-dimensional coordination polymers: Complexity and diversity in structures, properties, and applications. Chem. Rev. 2011, 111, 688-764. 
(40) Vittal, J. J.; Quah, H. S. Engineering solid state structural transformations of metal complexes. Coord. Chem. Rev. 2017, 342, 1-18.

(41) He, W. W.; Li, S. L.; Lan, Y. Q. Liquid-free single-crystal to single-crystal transformations in coordination polymers. Inorg. Chem. Front. 2018, 5, 279-300.

(42) CrysAlis PRO, Rigaku Oxford Diffraction, Yarnton, Oxfordshire, England, 2017.

(43) Sheldrick, G. M. A short history of SHELX. Acta Crystallogr. A, 2008, 64, 112-122.

(44) Sheldrick, G. M. Crystal structure refinement with SHELXL. Acta Crystallogr. C, 2015, $71,3-8$.

(45) Farrugia, L. J. WinGX and ORTEP for Windows: an update. J. Appl. Crystallogr. 2012, $45,849-854$.

(46) Spek, A. L. checkCIF validation ALERTS: what they mean and how to respond. Acta Crystallogr. E, 2020, 76, 1-11.

(47) Brandenburg, K. DIAMOND. Crystal Impact GbR, Bonn, Germany, 2006.

(48) Giannozzi, P. Andreussi, O.; Brumme, T.; Bunau, O.; Buongiorno Nardelli, M.; Calandra, M.; Car, R.; Cavazzoni, C.; Ceresoli, D.; Cococcioni, M.; Colonna, N.; Carnimeo, I.; Dal Corso, A.; de Gironcoli, S.; Delugas, P.; DiStasio, R.; Ferretti, A.; Floris, A.; Fratesi, G.; Fugallo, G.; Gebauer, R.; Gerstmann, U.; Giustino, F.; Gorni, T.; Jia, J.; Kawamura, M.; Ko, H.-Y.; Kokalj, A.; Küçükbenli, E.; Lazzeri, M.; Marsili, M.; Marzari, N.; Mauri, F.; and Nguyen, N. L.; Nguyen, H.-V.; Otero-de-la-Roza, A.; Paulatto, L.; Ponce, S.; Rocca, D.; Sabatini, R.; Santra, B.; Schlipf, M.; Seitsonen, A.; Smogunov, A.; Timrov, I.; Thonhauser, T.; Umari, P.; Vast, N.; Baroni, S. Advanced capabilities for materials modelling with Quantum ESPRESSO. J. Phys.: Condens. Matter, 2017, 29, 465901.

(49) Blöchl, P. E. Projector augmented-wave method. Phys. Rev. B, 1994, 50, 17953-17979. 
(50) Becke, A. D. On the large-gradient behavior of the density functional exchange energy. J. Chem. Phys. 1986, 85, 7184-7187.

(51) Perdew, J. P.; Burke, K.; Ernzerhof, M. Generalized gradient approximation made simple. Phys. Rev. Lett. 1996, 77, 3865-3868.

(52) Becke, A. D. Johnson, E. R. Exchange-hole dipole moment and the dispersion interaction revisited. J. Chem. Phys. 2007, 127, 154108.

(53) Otero-de-la-Roza, A.; Johnson, E. R. Van der Waals interactions in solids using the exchange-hole dipole moment model. J. Chem. Phys. 2012, 136, 174109.

(54) Otero-de-la-Roza, A.; Johnson, E. R.; Luaña, V. CRITIC2: A program for real-space analysis of quantum chemical interactions in solids. Comput. Phys. Commun. 2014, $185,1007-1018$.

(55) Johnson, E. R.; Keinan, S.; Mori-Sánchez, P.; Contreras-García, J.; Cohen, A. J.; Yang, W. Revealing noncovalent interactions. J. Am. Chem. Soc. 2010, 132, 6498-6506.

(56) Otero-de-la-Roza, A.; Johnson, E. R.; Contreras-García, J. Revealing non-covalent interactions in solids: NCI plots revisited. J. Phys. Chem. Chem. Phys. 2012, 14, $12165-12172$.

(57) Yu, M.; Trinkle, D. R. Accurate and efficient algorithm for Bader charge integration. $J$. Chem. Phys. 2011, 134, 064111.

(58) Groom, C. R.; Bruno, I. J.; Lightfoot, M. P.; Ward, S. C. The Cambridge Structural Database. Acta Crystallogr. Sect. B. Struct. Sci., Cryst. Eng. Mat. 2016, 72, 171-179.

(59) Turner, M. J.; Mckinnon, J. J.; Wolff, S. K.; Grimwood, D. J.; Spackman, P. R.; Jayatilaka, D.; Spackman, M. A. CrystalExplorer 17; The University of Western Australia, 2017. 
(60) Tan, S. L.; Jotani, M. M.; Tiekink, E. R. T. Utilizing Hirshfeld surface calculations, non-covalent interaction (NCI) plots and the calculation of interaction energies in the analysis of molecular packing. Acta Crystallogr. E, 2019, 75, 308-318.

(61) Jotani, M. M.; Wardell, J. L.; Tiekink, E. R. T. Supramolecular association in the triclinic $\left(Z^{\prime}=1\right)$ and monoclinic $\left(Z^{\prime}=4\right)$ polymorphs of 4-(4-acetylphenyl)piperazin-1ium 2-amino-4-nitrobenzoate. Z. Kristallogr. - Cryst. Mater. 2019, 234, 43-57.

(62) Pinto, C. B.; Dos Santos, L. H. R.; Rodrigues, B. L. Understanding metal-ligand inter-actions in coordination polymers using Hirshfeld surface analysis. Acta Crystallogr. C, 2019, 75, 707-716.

(63) Beckmann, P. A.; McGhie, A. R.; Rheingold, A. L.; Sloan, G. J.; Szewczyk, S. T. Solid-solid phase transitions and tert-butyl and methyl group rotation in an organic solid: x-ray diffractometry, differential scanning calorimetry, and solid-state $1 \mathrm{~h}$ nuclear spin relaxation. J. Phys. Chem. A, 2017, 121, 6220-6230.

(64) Kersten, K.; Kaur R.; Matzger, A. Survey and analysis of crystal polymorphism in organic structures. IUCrJ, 2018, 5, 124-129. 
For Table of Contents Use Only

Snap frozen! Capturing two metastable polymorphs in a tetramorphic one-dimensional coordination polymer constructed from cadmium, dithiophosphate, and 4pyridinealdazine

Yee Seng Tan, Alberto Otero-de-la-Roza Mukesh M. Jotani, and Edward R. T. Tiekink

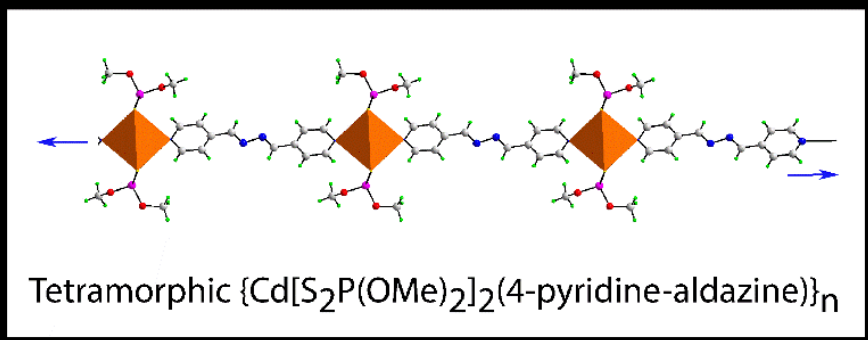

Room temperature $(\mathbf{1} \boldsymbol{\alpha})$ and three low temperature $(100 \mathrm{~K} ; \mathbf{1} \boldsymbol{\beta}, \mathbf{1} \boldsymbol{\gamma}$, and $\mathbf{1 \delta})$ polymorphs of a one-dimensional coordination polymer, $\left\{\mathrm{Cd}\left[\mathrm{S}_{2} \mathrm{P}(\mathrm{OMe})_{2}\right]_{2} \text { (4-pyridine-aldazine) }\right\}_{2}$, have been established. Two metastable forms are observed (1 $\gamma$ and $\mathbf{1 \delta})$ which convert to $\mathbf{1 \beta}$ upon heating (120-130 and 140-150 K, respectively) based on single crystal data. Forms $\mathbf{1} \boldsymbol{\alpha}$ and $\mathbf{1 \beta}$ undergo a reversible phase transition. 